

\title{
Função Composta Resolução em C
}

\author{
FÁBIO RIVAS CORREIA CERVINO \\ JAIDSON BRANDÃO DA COSTA
}




\section{$\int_{\text {presentação }}$}

Este livro tem como objetivo facilitar o ensino-aprendizado no que diz respeito às funções compostas, assunto abordado na disciplina de Matemática. Pensando na melhor maneira da elaboração, aplicação e resoluções de problemas envolvendo funções vislumbrou-se a junção dos conceitos e exercícios com uma abordagem em linguagem de programação de computadores e em especial a linguagem de programação C. Optouse por ela em virtude da execução em diversos sistemas operacionais de forma nativa. Para dinamizar as resoluções aplicaram-se alguns exemplos em programas em $\mathrm{C}$, a fim de que as soluções tenham inúmeros cenários com valores diferentes e assim demonstrando as resoluções dos problemas do mundo real e não apenas fixado ao um mero exercício, mas aplicado para que o aluno realize a implementação. Tendo em vista que há uma abordagem matemática e computacional neste livro, logo o público indicado para esta obra são alunos iniciantes em programação com bases matemáticas para o assunto de funções compostas. O livro foi elaborado por: Fábio Rivas Correia Cervino, Graduado em Matemática, Especialista em Gestão e Tutoria do Ensino a Distância e Mestre em Matemática e por Jaidson Brandão da Costa, Graduado em Sistemas de Informação, Especialista em Engenharia de Software e Mestre em Engenharia de Processos Industriais. Ambos Professores do Instituto Federal de Educação, Ciência e Tecnologia do Amazonas - Campus Avançado Manacapuru. 


\section{Sumário}

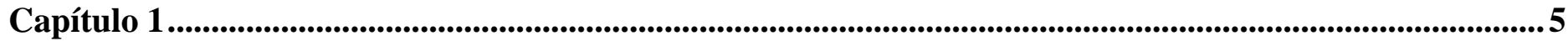

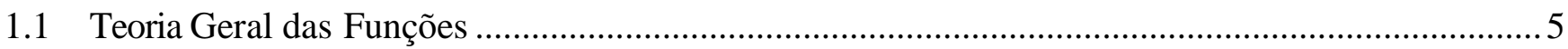

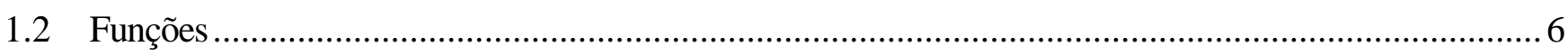

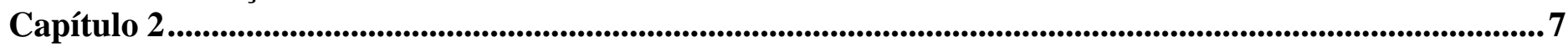

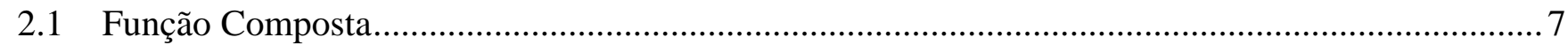

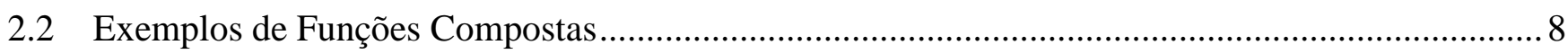

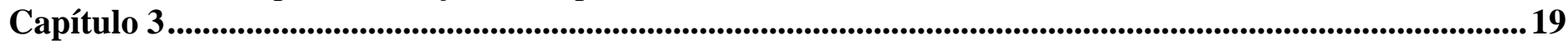

3.1 Tipos de Dados Básicos da Linguagem C ....................................................................... 19

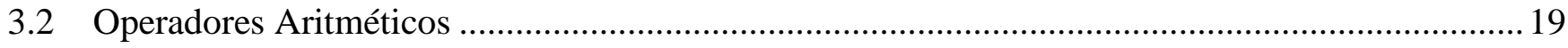

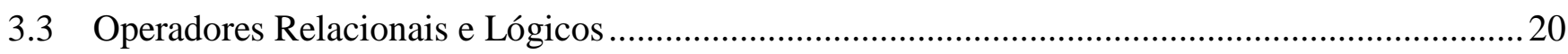

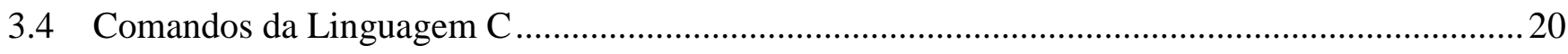

3.5 Exemplo de um código em Linguagem C .......................................................................... 20

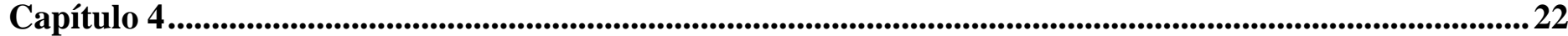

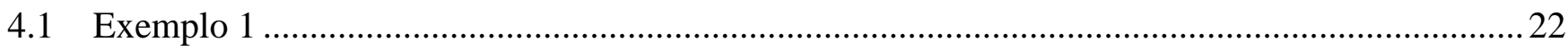

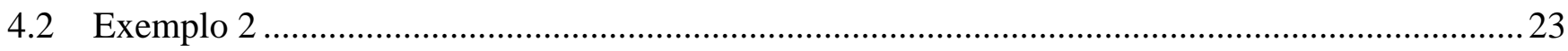

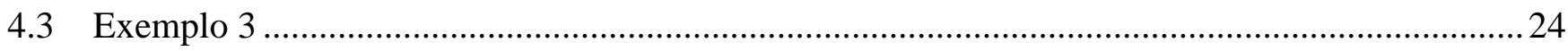

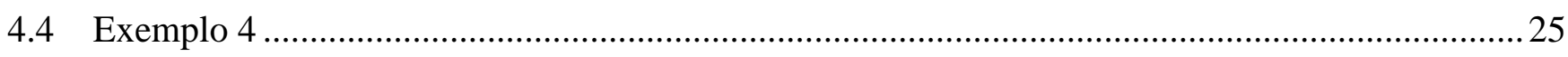

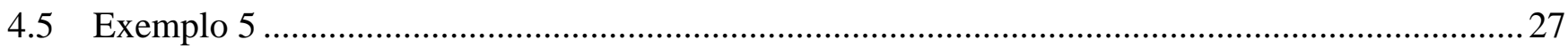

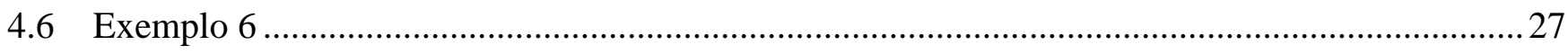

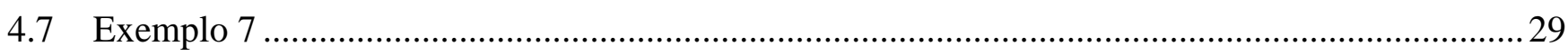

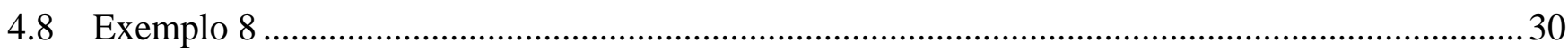

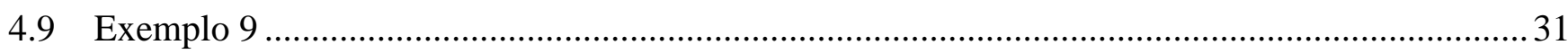

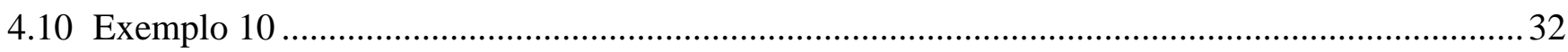

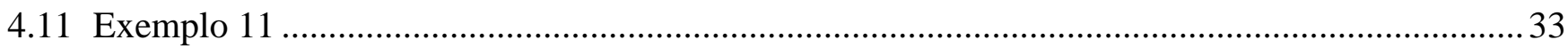

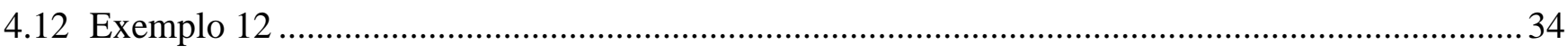

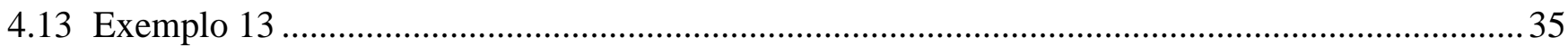

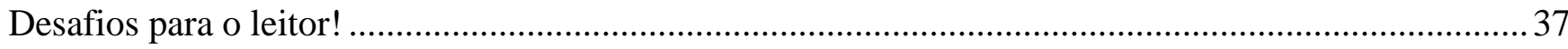

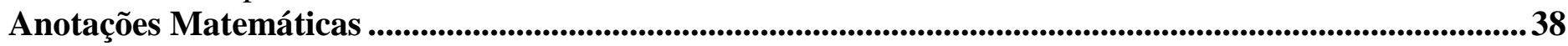

Anotações de Programação em C ...........................................................................................................................3 39

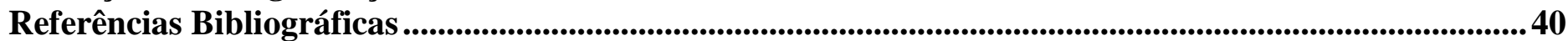




\section{Capítulo 1}

\section{Vamos Falar de Funções}

\subsection{Teoria Geral das Funções}

Se você perguntar a um matemático "raíz" o que é uma função provavelmente obterá a seguinte resposta: Dados dois conjuntos $A$ e $B$ o "comando matemático" que irá relacionar cada elemento de $A$ (Domínio) com um único elemento de $B$ (Contra-domínio) e a parte do conjunto $B$ que foi relacionada com o conjunto $A$ chamaremos de Imagem.

Matematicamente poderá ser definida uma função(f) da seguinte forma:

Definição 1. Dados A e B a relação

$$
f: \mathbf{A} \rightarrow \mathbf{B}
$$

será função se dado

$$
y=f(x) \forall x \text { S A } \exists \mid y \mathbf{S} \mathbf{B} \backslash x>\rightarrow f(x)
$$

Existe um aspecto positivo e outro nem tanto associados a essa resposta, como ideia que fortalece a resposta temos o fato de que a mesma é extremamente sucinta e pode ser entendida de forma fácil por pessoas que nem compartilham o mesmo idioma, porém se você não é muito atento a matemática estas notações supracitadas não devem fazer sentido algum para você, não é verdade?

Ainda existe outra maneira que a maioria dos matemáticos usará para desfazer o mal entendido, será apresentado um diagrama que se não for trabalhado com muito cuidado será construída uma limitação enorme nos conceitos de Domínio e imagem.

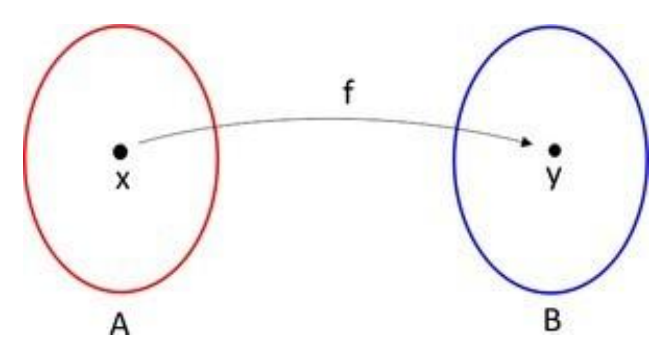

Figura 1.1: Diagrama de Venn Funções 
A figura acima é conhecida como Diagrama de Venn é uma ferramenta muito útil para o entendimento inicial do conteúdo de funções, porém se esta experiência não for bem conduzida há uma tendência de um entendimento reducionista, de tal forma que nos leve a pensar que tudo referente a domínio e imagem cabe dentro desses balões o que é absurdo.

Saindo um pouco da formalidade podemos entender o Domínio(D) como: se temos uma função de " $x$ " em " $y$ " todos os valores que se puder substituir no lugar de " $x$ " fazem parte do Domínio e a imagem são todos os resultados possíveis das aplicações dos valores de " $\mathrm{x}$ " nas funções.

Será que o estudo das funções foi iniciado com esse grau de formalismo? Ainda no campo da especulação, existem elementos práticos associados a esse conteúdo? As respostas são não e sim, pois no final do século XVII Gottfried Leibniz começa a comparar grandezas com curvas e chamar essa associação de função, de uma noção ainda meio que intuitiva que só adquiri um grau de formalismo maior quando o grande Leonhard Euler dá sua contribuição já no século XVIII que leva a noção mais formal supracitada neste texto. Ou seja, uma função pode ser qualquer coisa: desde um índice de tabagismo em função do tempo em uma certa localidade, quanto o deslocamento de um corpo em função do tempo como a variação do volume de um sólido de acordo com a variação da altura.

\subsection{Funções}

Do último ano do Fundamental e ao longo do Ensino Médio, geralmente estudamos doze funções, que são:

- Função constante;

- Função par;

- Função ímpar;

- Função afim ou polinomial do primeiro grau;

- Função Linear;

- Função crescente;

- Função decrescente;

- Função quadrática ou polinomial do segundo grau;

- Função modular;

- Função exponencial;

- Função logarítmica;

- Funções trigonométricas;

- Função raiz. 


\section{Capítulo 2}

\subsection{Função Composta}

Se as funções (f) como visto anteriormente levam valores de um conjunto A para certo conjunto $\mathrm{B}$, temos uma função que funciona como um atalho, pois se temos outra função $(\mathrm{g})$ que leva do conjunto $\mathrm{B}$ para o conjunto $\mathrm{C}$ isso tudo ocorrendo como etapas de um processo, porém em um dado momento seja necessário ir direto do conjunto A para o conjunto $\mathrm{C}$ poderemos estabelecer a função composta.

Matematicamente nós temos:

Definição

Definição 2. Dadas duas funções

$$
f: \mathbf{A} \rightarrow \mathbf{B} \text { e } g: \mathbf{B} \rightarrow \mathbf{C}
$$

Atribuímos o nome de função composta de f com g ou

$$
g(f(x))=(g \circ f)(x)
$$

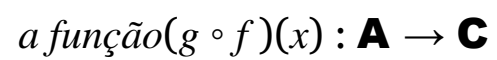

Graficamente pode ser analisada da seguinte forma:

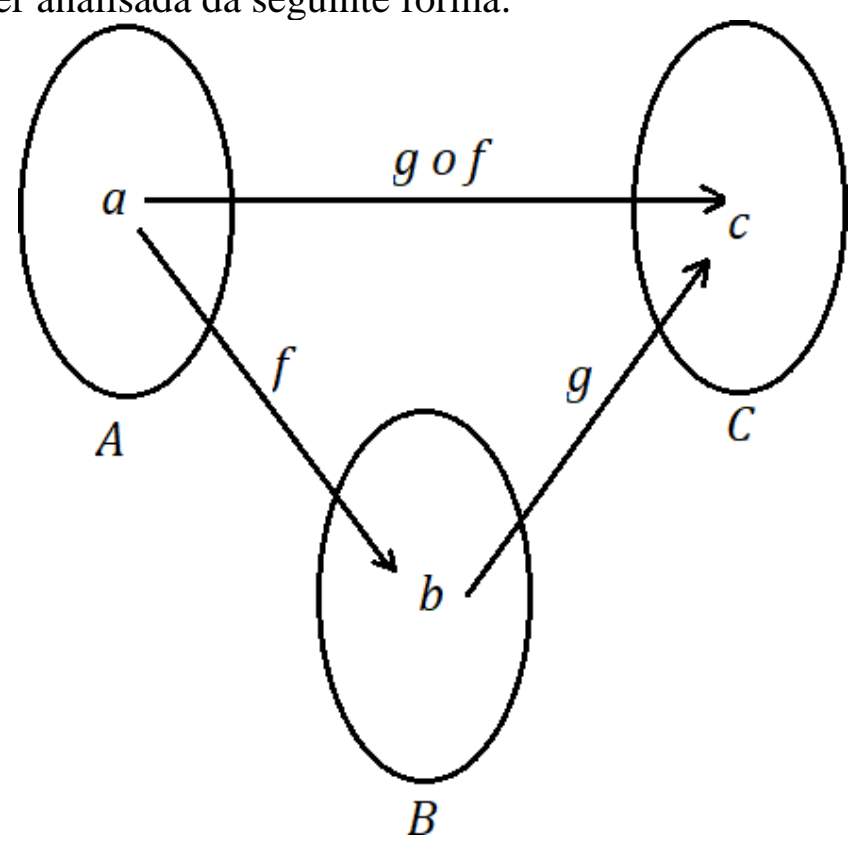

Figura 2.1: Diagrama de Venn Função Composta

Caso sejam necessárias funções para etapas intermediárias de um processo (f e g) e outra que leve do conjunto inicial ao final de forma direta $(\mathrm{g} \circ \mathrm{f}$ ) vemos a necessidade de compor as 
funcionais.

\subsection{Exemplos de Funções Compostas}

\section{Exemplo 1}

Suponha que certa empresa tenha um órgão de controle que esteja fiscalizando a parte de transporte desta empresa, que após estudo chega a conclusão que seus veículos percorrem em média $12 \mathrm{Km} / 1$ de combustível, sabe-se também que os veículos trafegam em velocidade média de $72 \mathrm{Km} / \mathrm{h}$. Determine:

a. A função que relaciona distância percorrida e tempo de percurso

b. A função que relaciona o consumo de combustível com a distância percorrida

c. O consumo por tempo de percurso e quanto combustível foi gasto em $8 \mathrm{~h}$ de viagem?

Solução a)

3. Como solução teremos uma função f de tal forma que:

$$
f(t)=d \mathrm{e} d=72 t
$$

onde d simboliza a distância em quilômetros e t simboliza o tempo em horas

Solução b)

4. Como solução desse item teremos uma função g de tal forma que:

$$
g(t)=c \text { e } c=\frac{t}{12}
$$

onde c simboliza o consumo em litros e t simboliza o tempo em horas

Solução b)

5. Como solução desse item utilizaremos os dois itens anteriores a função g de tal forma que:

$$
g(t)=c \text { e } c=\frac{t}{12}
$$

onde c simboliza o consumo em litros e t simboliza o tempo em horas e

$$
f(t)=d \text { e } d=72 t
$$

onde d simboliza a distância em quilômetros e t simboliza o tempo em horas desta forma ao compor uma nova função de g composta com f resolveremos o problema c) 


$$
\begin{gathered}
g{ }_{\circ}=\frac{72 t}{12} \\
g \circ f=6 t
\end{gathered}
$$

Após 8h tivemos o consumo de

\section{Exemplo 2}

$$
\begin{aligned}
& g \circ f=6.8 \\
& g \circ f=48 l
\end{aligned}
$$

Em uma certo setor de uma fabrica de brinquedos são produzidos 10 moduladores de voz de um certo robô de brinquedo a cada hora. Por modulador a fábrica cobra $\mathrm{R} \$ 150,00$.

a) Determine a quantidade (q) de moduladores produzidos em função do tempo (t) em horas.

b) Determine a função que relaciona a arrecadação (a) com a quantidade de peças (q).

c) Estabeleça a função que retorna o valor da arrecadação (a) em função do tempo (t) e dê o valor arrecadado após 8 h de trabalho.

Solução a)

6. Como solução teremos uma função q(t) de tal forma que:

$$
q(t)=10 t
$$

, pois o maquinário produz 10 moduladores a cada hora, por isso estamos multiplicando essa produção pelo número de horas

Solução b)

7. Como solução desse item teremos uma função g de tal forma que:

$$
g(q)=150 q
$$

, pois a fábrica vende cada modulador por $\$ 150,00$

Solução c)

8. Como solução desse item utilizaremos os dois itens anteriores a função g de tal forma que:

$$
g(p)=150 p \text { e } q(t)=10 t
$$

onde

$$
\begin{gathered}
g \circ q=g(q(t))=150 . q(t)=150.10 t=1500 t \\
g \circ q=1500 t
\end{gathered}
$$


que simboliza a arrecadação financeira em função do tempo, em horas Após 8 h de trabalho tivemos a arrecadação de

$$
\begin{gathered}
g \circ q(8)=1500.8 \\
g \circ q(8)=\$ 12000,00
\end{gathered}
$$

que simboliza a arrecadação em uma jornada de trabalho legal.

Exemplo 3

Certa indústria de calçados, o custo de produção dos sapatos é $\$ 400,00$ fixo e mais $20 \%$ por unidade. Nessa indústria temos lotes de 500 peças, e são vendidos com $20 \%$ de lucro sobre o preço de custo.

a) Escreva o custo (c) em função do número de peças (p) produzidas.

b) Escreva a arrecadação das vendas (v) em função do custo (c).

c) Qual a função que representa o valor arrecadado nas vendas em função do número de sapatos produzidos e qual o valor arrecadado na venda de um lote?

Solução a)

9. Como solução teremos uma função $C(p)$ de tal forma que:

$$
C(p)=0,2 p+400
$$

, pois sendo $\$ 400,00$ o custofixo da produção e mais $20 \%$ que equivale $a^{20}=0,2$ por isso multiplicamos 100

Solução b)

10. Como solução desse item teremos uma função $V(c)$ de tal forma que:

$$
V(c)=1,2 c
$$

, pois preço de venda é igual a custo mais lucro, ou seja,

$$
V(c)=c+\frac{20}{100} c=c+0.2 c=1,2 c
$$

como havíamos definido inicialmente.

Solução c)

11. Como solução desse item utilizaremos os dois itens anteriores a função $V(c)$ de tal forma que: 
Onde

$$
V(c)=1,2 c \text { e } C(p)=0,2 p+400
$$

$$
\begin{gathered}
\mathrm{V} \circ \mathrm{C}=\mathrm{V}(\mathrm{C}(\mathrm{p}))=1,2(\mathrm{o}, 2 \mathrm{p}+400)=0,23 \mathrm{p}+480 \\
\mathrm{~V} \circ \mathrm{C}=0,24 \mathrm{p}+480
\end{gathered}
$$

que simboliza a arrecadação financeira nas vendas em função número de peças produzidas. Já em um lote que contém 500 sapatos arrecadaremos com as vendas

$$
\begin{gathered}
V \circ C(500)=0,24.500+480 \\
V \circ C(500)=120,00+480 \\
V \circ C(500)=\$ 600,00
\end{gathered}
$$

que simboliza a arrecadação das vendas em um lote produzido.

Exemplo 4

(Uerj) Admita os seguintes dados sobre as condições ambientais de uma comunidade, com uma população $\mathrm{p}$, em milhares de habitantes:

- C, a taxa média diária de monóxido de carbono no ar, em partes por milhão, corresponde a $\mathrm{C}(\mathrm{p})=0,5 \mathrm{p}+1$;

- em um determinado tempo $\mathrm{t}$, em anos, $\mathrm{p}$ será igual a $\mathrm{p}(\mathrm{t})=10+0,1 \mathrm{t}^{2}$. Relacionado com taxa $\mathrm{C}$

a) expresse-a como uma função do tempo;

b) calcule em quantos anos essa taxa será de 13,2 partes por milhão.

Solução a) Para solucionar esse item utilizaremos a composição da função $C(p)$ com a função $p(t)$ :

$$
C(p)=0,5 p+1 \mathrm{e} p(t)=10+0,1 t^{2}
$$

onde

$$
\begin{gathered}
C \circ p=C(p(t))=0,5\left(10+0,1 t^{2}\right)+1=5+0,05 t^{2}+1=6+0,05 t^{2} \\
C(t)=0,05 t^{2}+6
\end{gathered}
$$


Solução b)

13. Para solucionar o item devemos resolver a seguinte equação

$$
\begin{gathered}
13,2=0,05 t^{2}+6 \\
0,05 t^{2}-7,2=0 \\
0,05 t^{2}=7,2 \\
t^{2}=\frac{7,2}{0,05} \\
t^{2}=144 \\
t=12 \text { dias }
\end{gathered}
$$

\section{Exemplo 5}

(Uff) No processo de respiração do ser humano, o fluxo de ar através da traqueia, durante a inspiração ou expiração, pode ser modelado pela função $\mathrm{F}$, definida, em cada instante $\mathrm{t}$, por $\mathrm{F}(\mathrm{t})$ $=\mathrm{M}$ sen wt.A pressão interpleural (pressão existente na caixa torácica), também durante o processo de respiração, pode ser modelada pela função $\mathrm{P}$, definida, em cada instante $\mathrm{t}$, por $\mathrm{P}(\mathrm{t})=$ $\mathrm{L}-\mathrm{F}(\mathrm{t}+\mathrm{a})$. As constantes a, $\mathrm{L}, \mathrm{M}$ e w s?o reais, positivas e dependentes das condições fisiológicas de cada indivíduo.(AGUIAR, A.F.A., XAVIER, A.F.S. e RODRIGUES, J.E.M. Cálculo para Ciências Médicas e Biológicas, ed. HARBRA Ltda. 1988.(Adaptado)Um possível gráfico de $\mathrm{P}$, em função de t, é:

a)

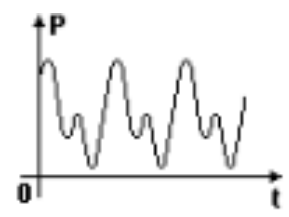

b)

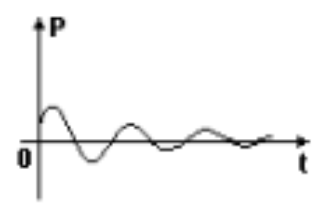

c)

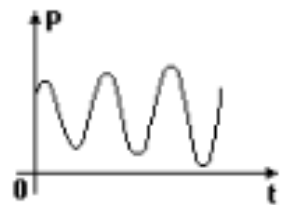

d)

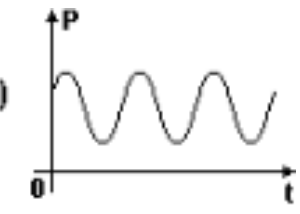

e)

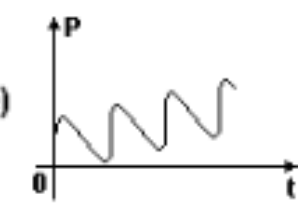

Figura 2.2: Gráficos

Solução

14. Para solucionar esse item analisaremos a composição das funções $P$ e $F$ por uma perspectiva diferente se $F(t)=M$ sen wt, então $F(t+a)=M \operatorname{sen}[w(t+a)]$, ou seja $F(t$ 
$+a)=M \operatorname{sen}(W t+W a)$, como $P(t)=L-F(t+a), \operatorname{logo} P(t)=L-M \operatorname{sen}(w t+w a)$ não passa de uma função seno com amplitude transladada e frequência alterada, porém ambas continuam constantes. (Portanto resposta letra d)

Exemplo 6

$\operatorname{Dadas} f: \mathbf{R} \rightarrow \mathbf{R}$ e $g: \mathbf{R} \rightarrow \mathbf{R}$ onde $f(x)=2 x^{2}-8$ e $g(x)=x+1$.

Determine:

a) quais as leis de formação de $f(g(x))$ e de $g(f(x))$;

b) o valor de $f(g(2))$ e $g(f(1))$

Solução a)

15. Para solucionar esse item utilizaremos a técnica clássica de composição de funções

$$
\begin{gathered}
f(g(x))=2 \cdot(x+1)^{2}-8 \\
f(g(x))=2 \cdot\left(x^{2}+2 \cdot x \cdot 1+1^{2}\right)-8 \\
f(g(x))=2 \cdot\left(x^{2}+2 x+1\right)-8 \\
f(g(x))=2 x^{2}+4 x+2-8 \\
f(g(x))=2 x^{2}+4 x-6 \\
g(f(x))=2 x^{2}-8+1 \\
g(f(x))=2 x^{2}-7 \\
\end{gathered}
$$


Solução b)

16. Para solucionar o item devemos resolver a seguinte equação

$$
\begin{gathered}
f(g(2))=2.4^{2}+4.2-6 \\
f(g(2))=2.16+8-6 \\
f(g(2))=32+2 \\
f(g(2))=34 \\
g(f(1))=2.1^{2}-7 \\
g(f(1))=2-7 \\
g(f(1))=-5
\end{gathered}
$$

Exemplo 7

$$
\text { Dadas }: \mathbf{R} \rightarrow \mathbf{R} f(x)=2 x-5 \text { e } g: \mathbf{R} \rightarrow \mathbf{R}
$$

$\backslash f \circ g=2 x^{2}+6$. Encontre a lei de formao de $g$.

Solução

17. Para solucionar o item devemos entender que segundo o problema:

$$
f(g(x))=2 x^{2}+6, \text { enquanto } f(x)=2 x-5
$$

logo devemos colocar $g(x)$ no lugar de $x$ da função fe ao isolar o g teremos nossa solução.

$$
\begin{gathered}
f(g(x))=2 g(x)-5 \\
2 x^{2}+6=2 g(x)-5 \\
2 x^{2}+6+5=2 g(x) \\
g(x)=x^{2}+\frac{11}{2}
\end{gathered}
$$

Exemplo 8

(ITA)(Adaptado) Sejam $\mathrm{f}(\mathrm{x})=\mathrm{x}^{2}+1 e(x)=x-1$ dois funcionais reais. Definimos a composta entre $f$ e $g g g(f(x))$. logo determine o valor de $(y-1)$. 
Solução

18.

$$
\begin{gathered}
g \circ f(x)=x^{2}+1-1 \\
g \circ f(x)=x^{2} \\
g \circ f(y-1)=(y-1)^{2} \\
g \circ f(y-1)=y^{2}-2 y+1
\end{gathered}
$$

Exemplo 9

(FCG) As funções

$$
f e g,: \mathbf{R} \rightarrow \mathbf{R} \text {, definidas por } f(x)=2 x+3 e g(x)=3 x+m . \operatorname{Se} f(g(x))=g(f(x))
$$

, logo f(m) é um número:
a) primo
b) negativo
c) cubo perfeito
d) menor que 18
e)múltiplo de 12

Solução

19.

$$
\begin{gathered}
g \circ f(x)=3(2 x+3)+m \\
g \circ f(x)=6 x+9+m \\
f \circ g(x)=2(3 x+m)+3 \\
f \circ g(x)=6 x+2 m+3 \\
\text { para que } f \circ g(x)=g \circ f(x) \text { temos : } \\
9+m=2 m+3 \\
9-3=2 m-m \\
6=m \\
f(6)=2.6+3 \\
f(6)=12+3 \\
f(6)=15
\end{gathered}
$$

resposta letra d) menor que 18 
exemplo 10

(ANGLO) Sendo f e $g$ funções de

$\mathbf{R}-\rightarrow \mathbf{R}$, tais que $f(x)=3 x-1$ e $g(x)=x^{2}$, o valor de $f(g(f(1)))$
a) 10
b) 11
c) 12
d) 13
e) 14

Solução

20.

$$
\begin{gathered}
g \circ f(x)=(3 x-1)^{2} \\
g \circ f(x)=9 x^{2}-6 x+1 \\
f(g(f(x)))=3\left(9 x^{2}-6 x+1\right)-1 \\
f(g(f(x)))=27 x^{2}-18 x+3-1 \\
f(g(f(1)))=27.1^{2}-18.1+3-1 \\
f(g(f(1)))=27-15 \\
f(g(f(1)))=12
\end{gathered}
$$

resposta letra c) igual a 11

Exemplo 11

(MACK-02) Se

$$
x>1 \text { e } f(x)=\frac{x}{x-1}, \log f(f(x+1)) \text { igual a : }
$$

a) $x+1$

b) $\frac{1}{x-1}$

c) $x-1$

d) $\frac{x}{(x-1)}$

$e) \frac{(x+1)}{(x-1)}$

Solução 
21.

$$
\begin{gathered}
f(x+1)=\frac{x+1}{x+1-1} \\
f(x+1)=\frac{x+1}{x} \\
f(f(x+1))=\frac{\frac{x+1}{x}}{\frac{x+1-1}{x-1}} \\
f(f(x+1))=\frac{\frac{x+1}{x}}{x-1} \\
f\left(f(x+1)=\left(\frac{x+1}{x}\right) *\left(\frac{x-1}{x}\right)\right. \\
f\left(f(x+1)=\frac{x+1}{x-1}\right.
\end{gathered}
$$

resposta letra e)

\section{Exemplo 12}

(UFMG) Para função $f(x)=5 x+3$ e um número $b$, tem-se $f(f(b))=-2$. o valor de $b$ é:
a) 1
b) $-\frac{4}{5}$
c) $-\frac{17}{25}$
d) $-\frac{1}{5}$
e)2

Solução

22.

$$
f(f(x))=5(5 x+3)+3
$$




$$
\begin{gathered}
f(f(x))=25 x+15+3 \\
f(f(x))=25 x+18 \\
f(f(b))=25 b+18
\end{gathered}
$$

$e$

$$
f(f(b))=2
$$

segundo o enunciado,

$$
\begin{gathered}
25 b+18=-2 \\
25 b=-2-18 \\
25 b=-20 \\
b=-\frac{20}{25} \\
b=-\frac{4}{5}
\end{gathered}
$$

resposta letra $b$

Exemplo 13

(UFMG) Para um número real fixo a, a função $\mathrm{f}(\mathrm{x})=\mathrm{ax}-2$ é tal que $\mathrm{f}(\mathrm{f}(1))=-3$. O valor de a é:
a) 1
b) 2
c) 3
d) 4
e) 5

Solução

23.

$$
\begin{aligned}
& f(f(x))=a(a x-2)-2 \\
& f(f(x))=a^{2} x-2 a-2
\end{aligned}
$$

$e$

$$
f(f(1))=-3
$$

, $\log o$

$$
\begin{gathered}
a^{2} .1-2 . a-2=-3 \\
a^{2}-2 a+1=0
\end{gathered}
$$

Temos uma equação quadrática onde a soma s das raízes é igual a 2 e o produto das raízes pé igual a 1, logo as raízes são iguais a 1.

resposta letra a) 


\section{Capítulo 3}

\section{Vamos Falar de Linguagem C}

Os programadores escrevem instruções em várias linguagens de programação, algumas entendidas diretamente pelo computador e outras que exigem passos intermediários de tradução. Essas linguagens computacionais estão atualmente em uso. E são divididas em três tipos gerais:

\section{Linguagens de máquina}

\section{Linguagens assembly}

\section{Linguagens de alto nível}

A linguagem C foi criada a partir do B por Dennis Ritchie, do Bell Laboratories, e implementada originalmente em 1972. O C se tornou conhecido como a linguagem de desenvolvimento do sistema operacional UNIX. O C independe do hardware. Elaborando um projeto cuidadoso, é possível escrever programas em $\mathrm{C}$ que sejam portáteis para a maioria dos computadores. Ele usa muitos dos importantes conceitos do BCPL e do B.

\subsection{Tipos de Dados Básicos da Linguagem C}

Para utilização da linguagem C é necessário sabermos os tipos de dados para as variáveis que desejamos usar, assim possamos obter resultados satisfatórios. Logo abaixo são mostrados os tipos:

\begin{tabular}{cc}
\hline Tipo & Bits necessários para armazenamento \\
\hline char & 8 \\
int & 16 \\
float & 32 \\
double & 64 \\
void & 0 \\
\hline
\end{tabular}

\subsection{Operadores Aritméticos}

Para realizarmos operações aritméticas precisamos conhecer os operadores disponíveis em C destacados logo abaixo:

\begin{tabular}{cc}
\hline Operador & Significado \\
\hline+ & Adição \\
$*$ & Multiplicação \\
$/$ & Divisão \\
\hline
\end{tabular}




\begin{tabular}{cc}
\hline$\%$ & Resto da Divisão Inteira \\
- & Subtração \\
-- & Decremento \\
++ & Incremento \\
\hline
\end{tabular}

\subsection{Operadores Relacionais e Lógicos}

As operações de relação e lógicos em C são exibidas logo abaixo:

\begin{tabular}{cc}
\hline Operador & Significado \\
\hline$>$ & Maior que \\
$>=$ & Maior ou Igual que \\
$<$ & Menor que \\
$<=$ & Menor ou Igual que \\
$==$ & Igual a que \\
$!=$ & Diferente de \\
$\& \&$ & Conjunção E \\
$\|$ & Conjunção OU \\
$!$ & Não \\
\hline
\end{tabular}

\subsection{Comandos da Linguagem $\mathrm{C}$}

As operações de relação e lógicos em C são exibidas logo abaixo:

\begin{tabular}{cc}
\hline Comando & Significado \\
\hline scanf & Ler dados \\
printf & Escrever dados \\
if & Condição se \\
switch & Escolha casos \\
for & Laço de repetição for \\
while & Laço de repetição while \\
\{ & Inicio \\
\}| & Fim \\
// & Comentário \\
$\%$ c & Leitura de caracter \\
$\%$ f & Leitura de números inteiros \\
$\%$ s & Leitura de números reais \\
\& & Leituras de caracteres \\
\hline
\end{tabular}

\subsection{Exemplo de um código em Linguagem $\mathrm{C}$}

Para compreendermos as estruturas da linguagem $\mathrm{C}$ nada melhor do que o código para exemplificar, logo as seguir será demonstrado um algoritmo para leitura e exibição de um número na tela. 


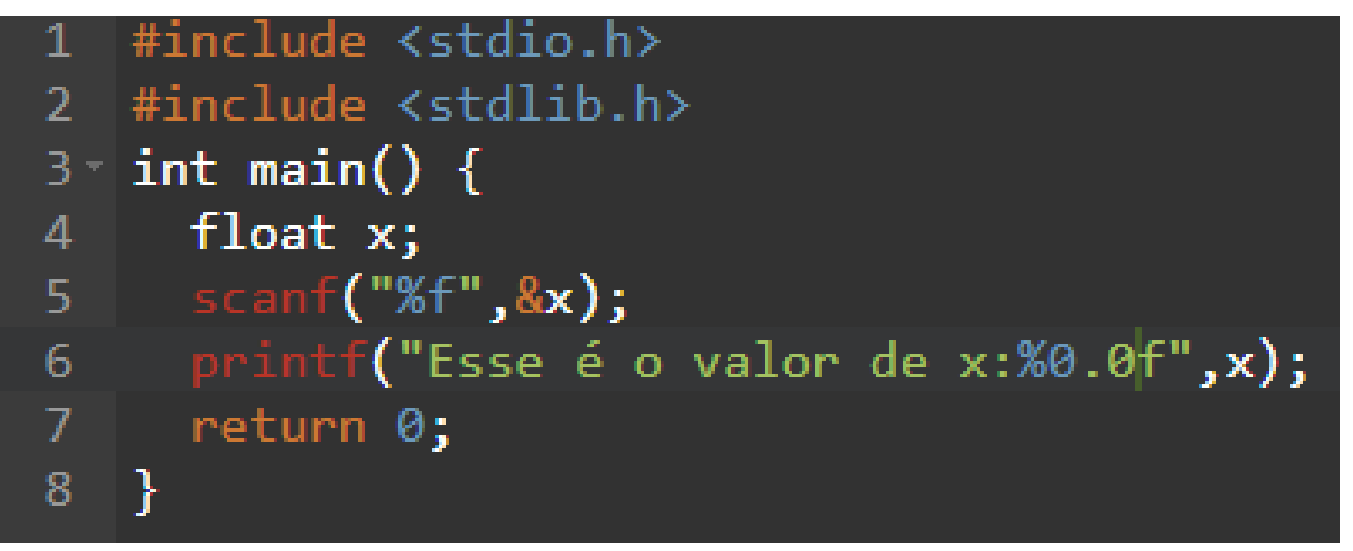

Figura 3.1: Código em C

Exibição do resultado do código depois de compilado e executado:

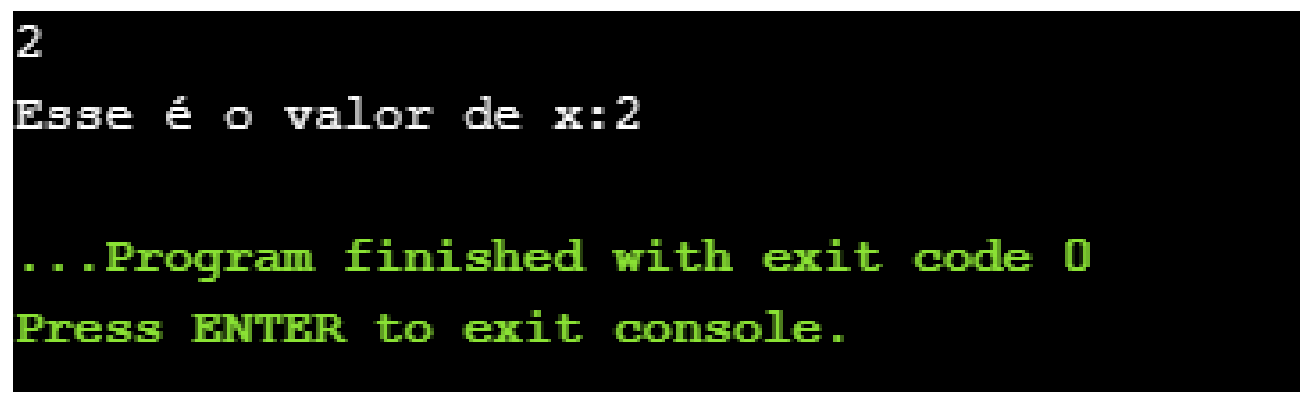

Figura 3.2: Código em C compilado e executado

Para o desenvolvimento de códigos em uma linguagem de programação é necessário que seja utilizado um ambiente de produção de código que nada mais é do que um software especifico para a compilação, interpretação e execução do programa. Utilizou-se o compilador Dev C++ por ser General Public License - GNU, isto é a licença destina-se a garantir a sua liberdade de compartilhar e alterar livremente. A figura abaixo ilustra a interface do compilador.

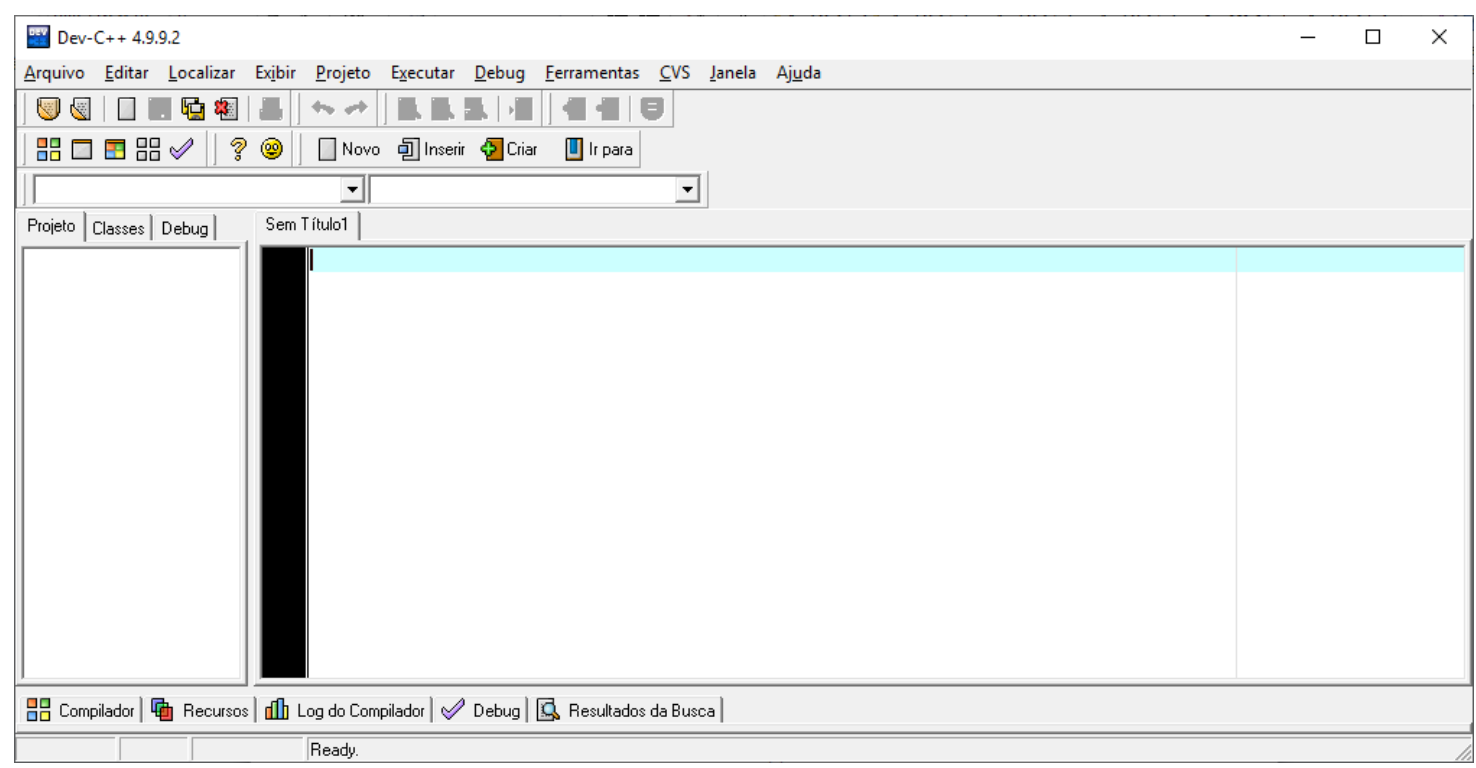

Figura 3.2: Dev C++ 


\section{Capítulo 4}

\section{Vamos Aplicar na Linguagem $C$ os Exemplos do Capítulo 2}

Neste capitulo veremos o desenvolvimento dos códigos no Dev C++ na linguagem C inerente aos exemplos do capitulo 2 para facilitar as mudanças de valores para verificação de inúmeros cenários a serem explorados pelo professores e alunos tanto das disciplinas de Matemática quanto de Informática.

\subsection{Exemplo 1}

Resolução em C e sua execução:

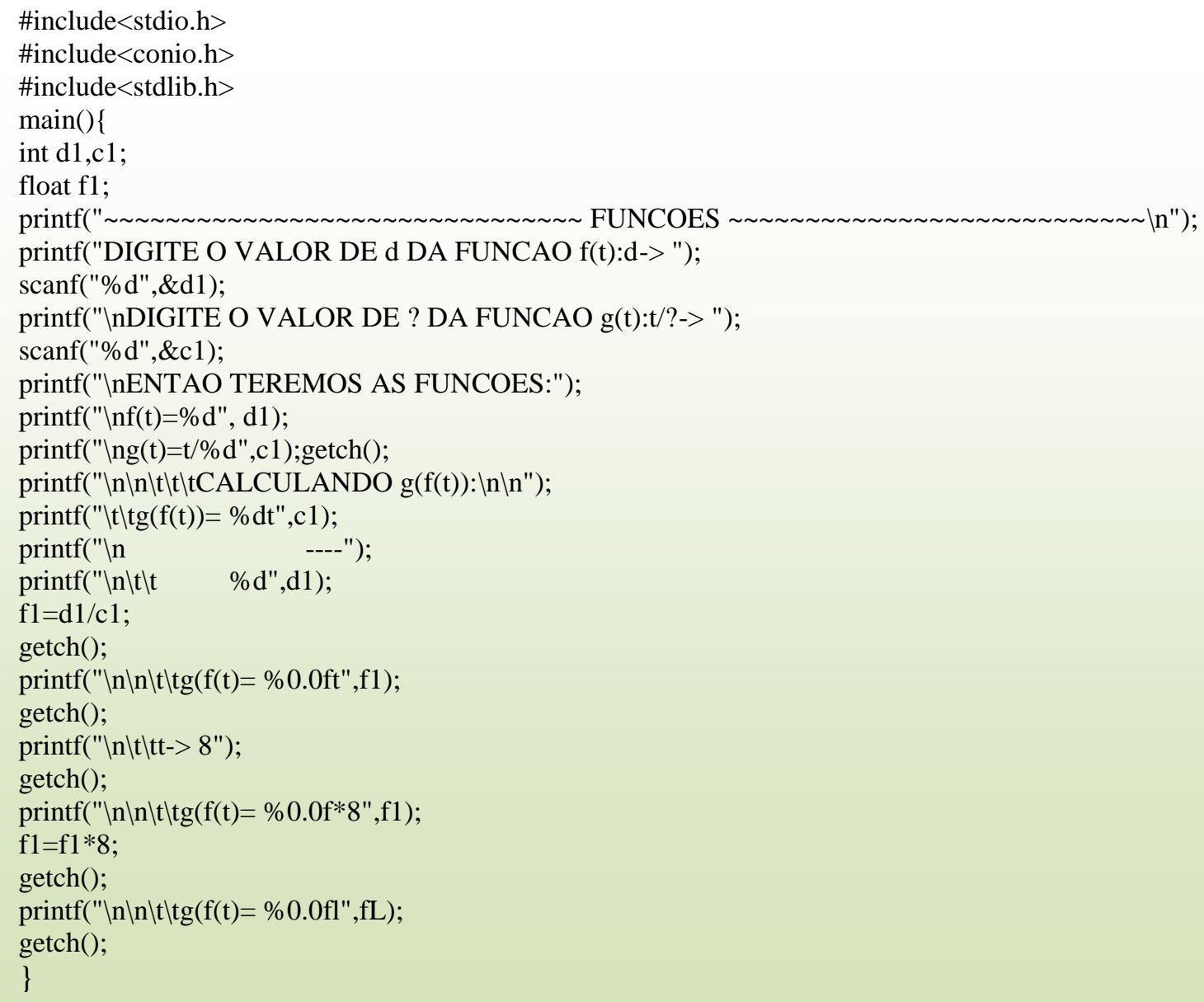

Figura 4.1: Exemplo 1 em C

Resultado da execução do programa do Exemplo 1: 


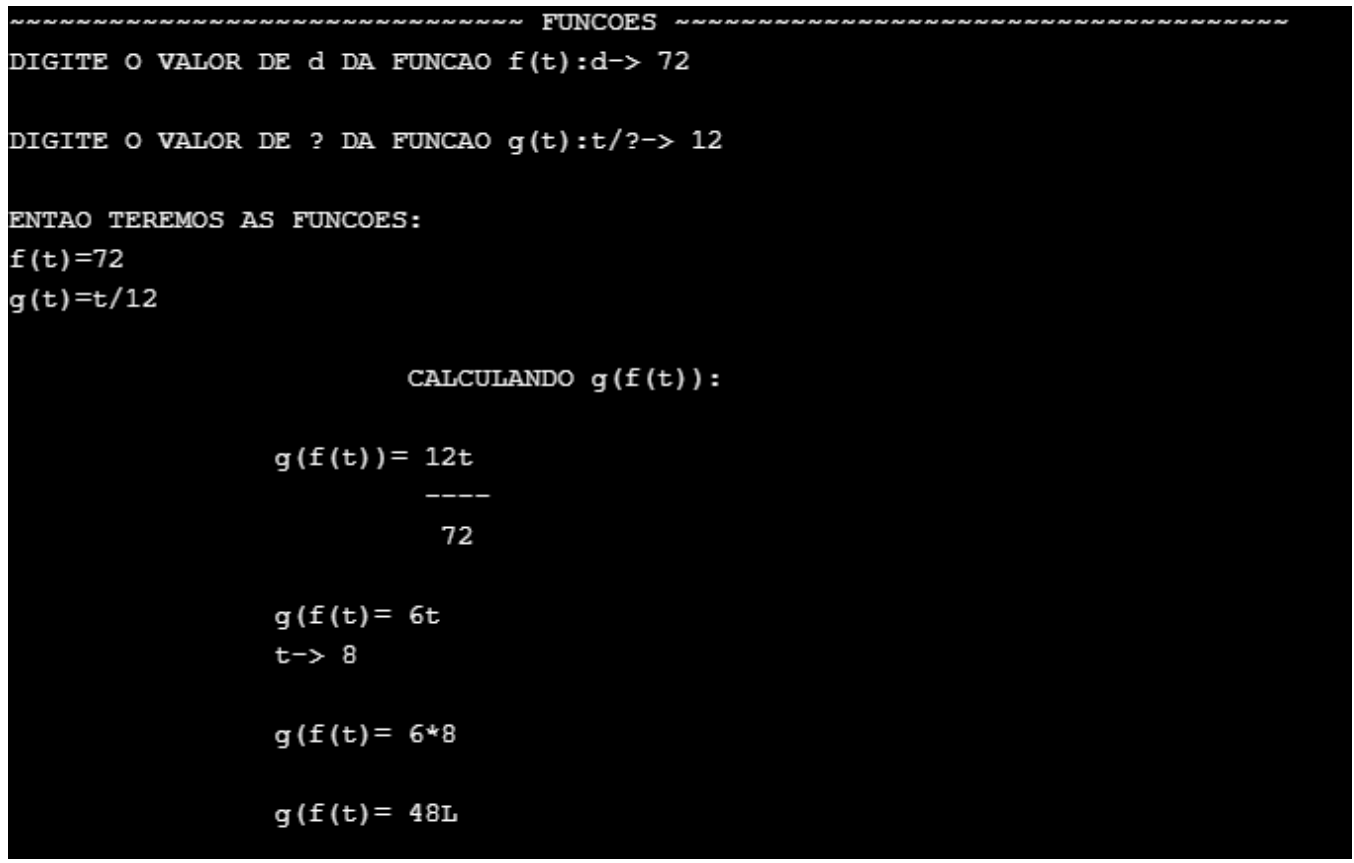

Figura 4.2: Resultado da execução do Exemplo 1 em C

\subsection{Exemplo 2}

Resolução em C e sua execução:

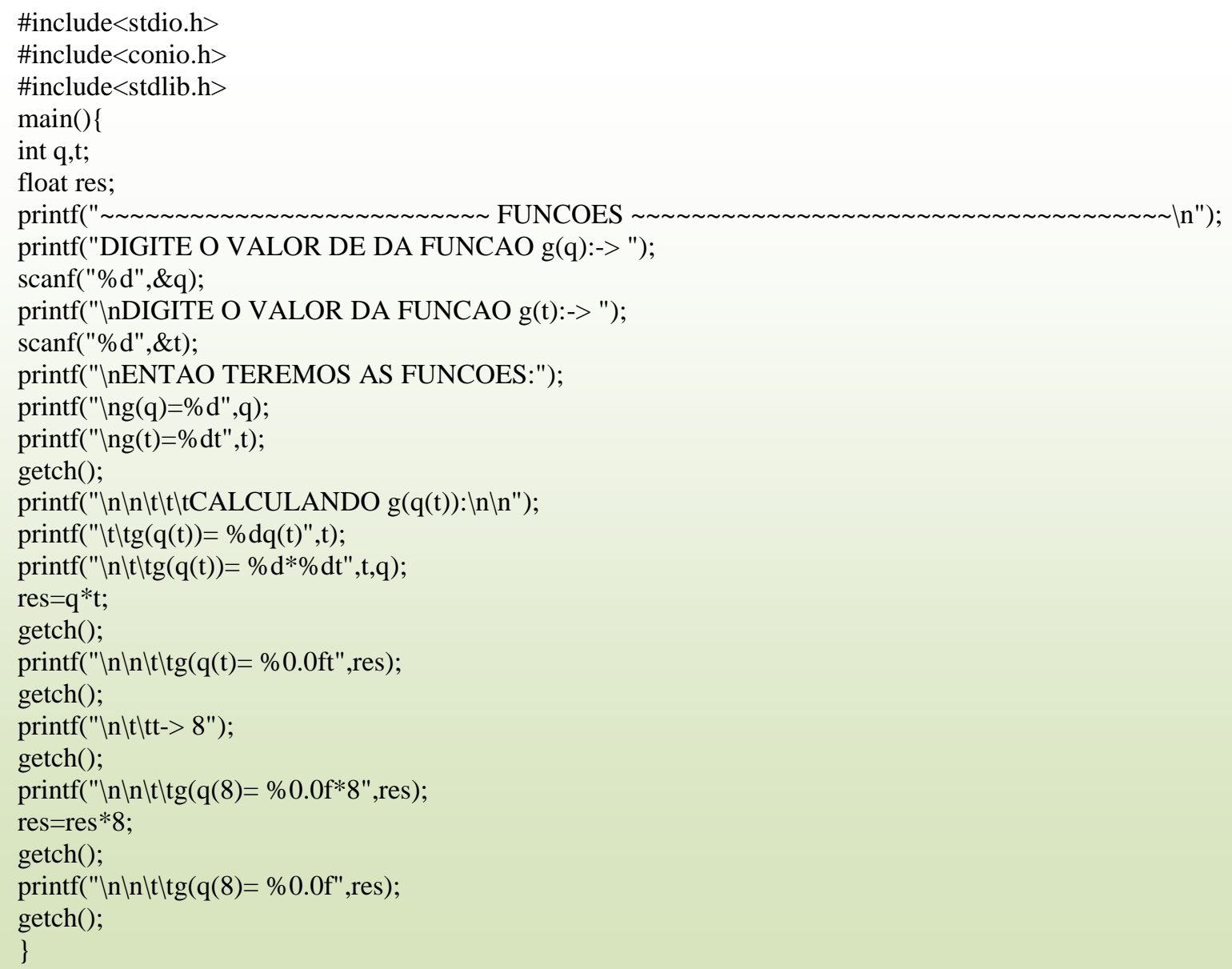

Figura 4.2: Exemplo 2 em C

Resultado da execução do programa do Exemplo 2: 


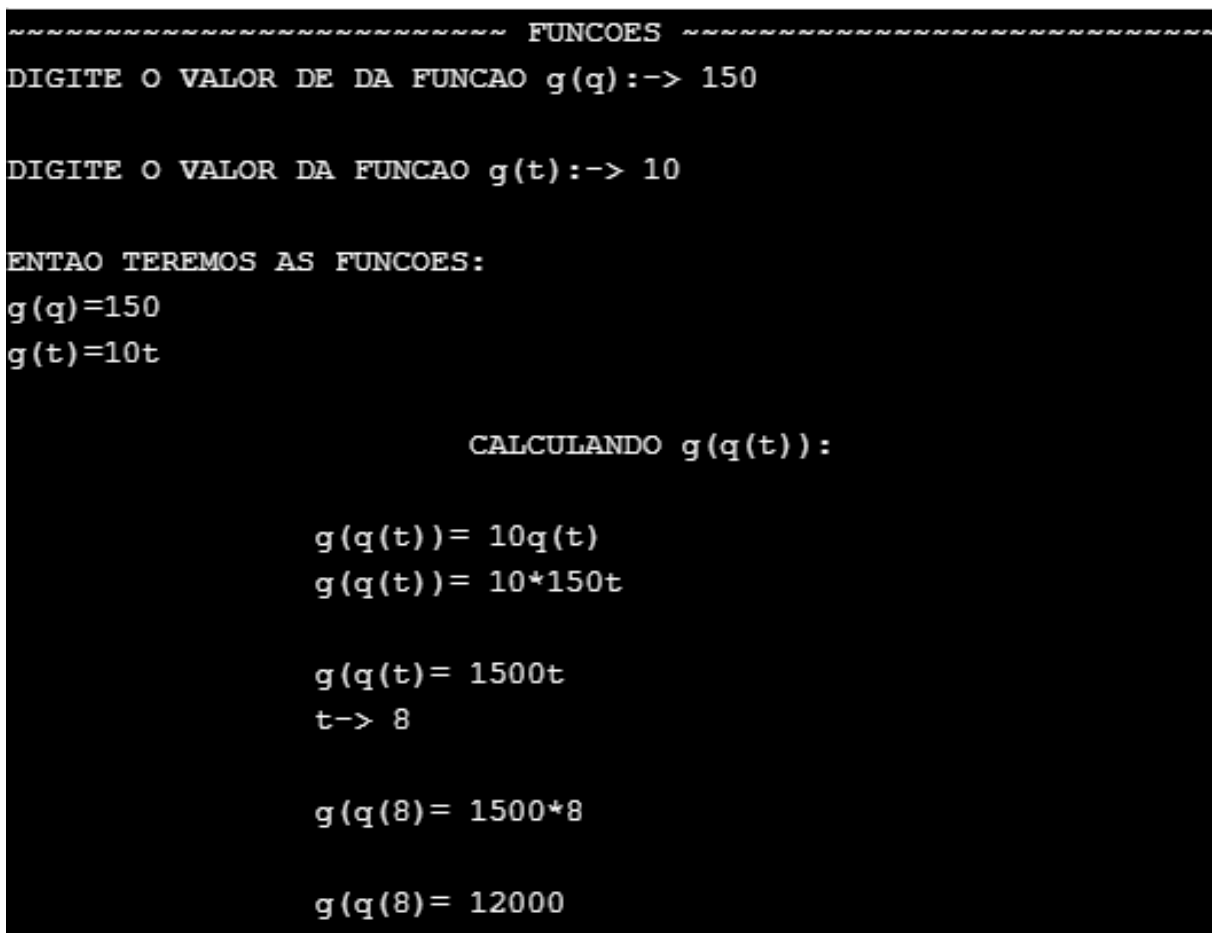

Figura 4.3: Resultado da execução do Exemplo 2 em C

\subsection{Exemplo 3}

Resolução em C e sua execução:

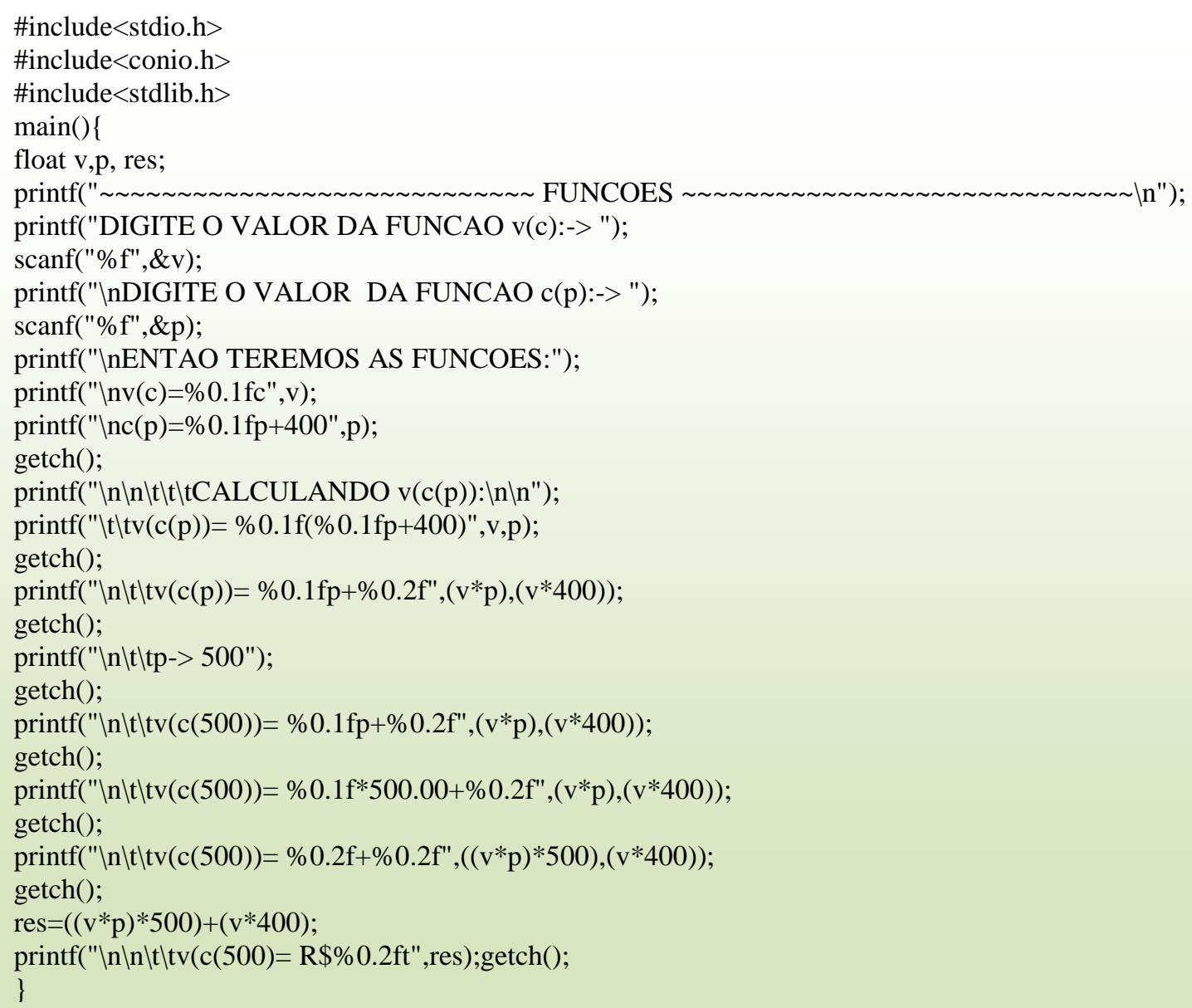

Figura 4.4: Exemplo 3 em C

Resultado da execução do programa do Exemplo 3: 


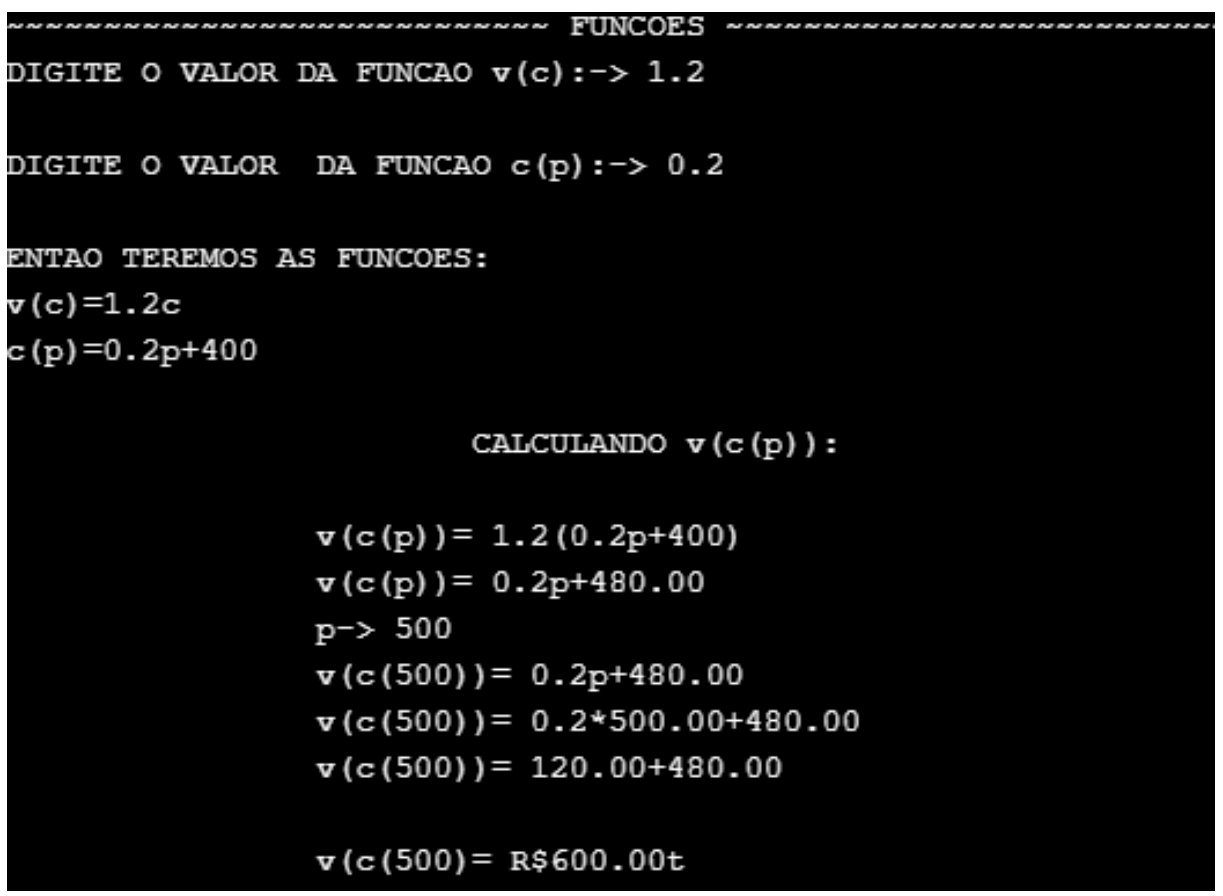

Figura 4.5: Resultado da execução do Exemplo 3 em C

\subsection{Exemplo 4}

Resolução em C e sua execução em duas partes:

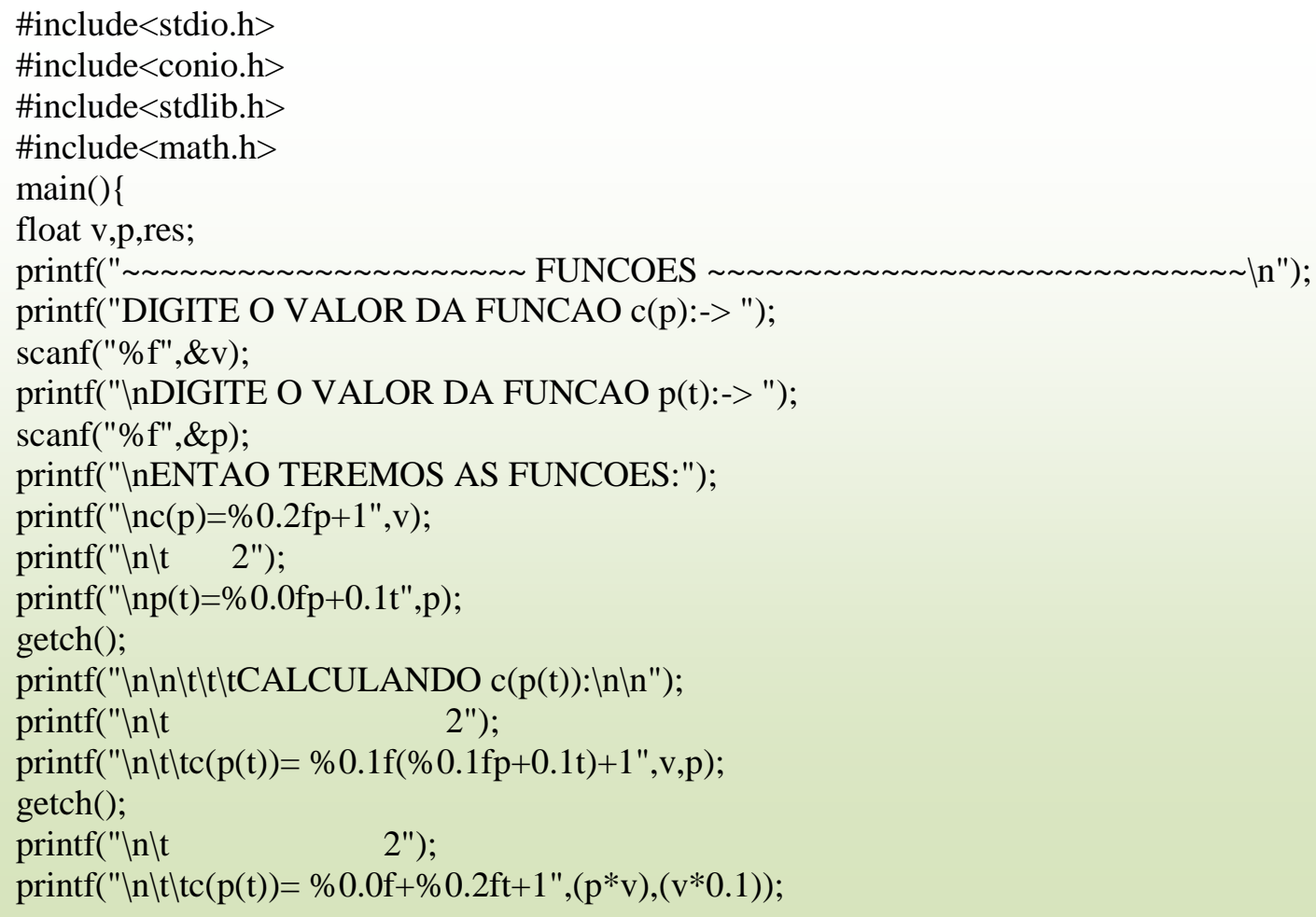

Figura 4.6: Exemplo 4 em C - Parte 1 


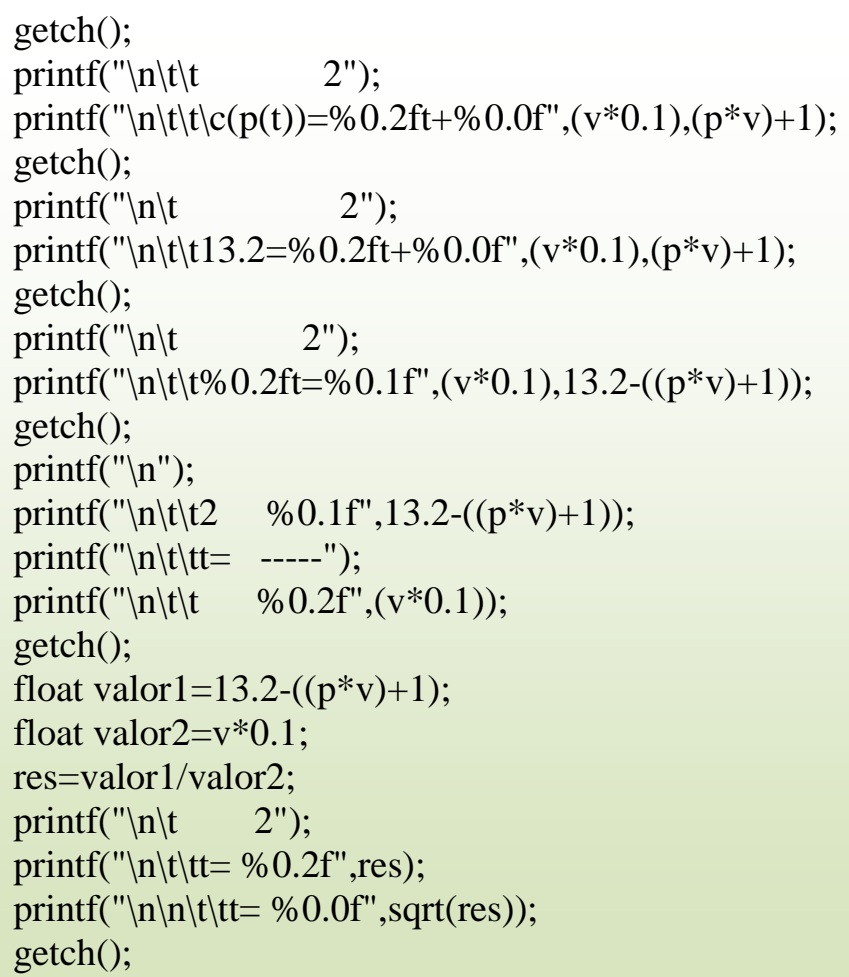

Figura 4.7: Exemplo 4 em C - Parte 2

Resultado da execução do programa do Exemplo 4:

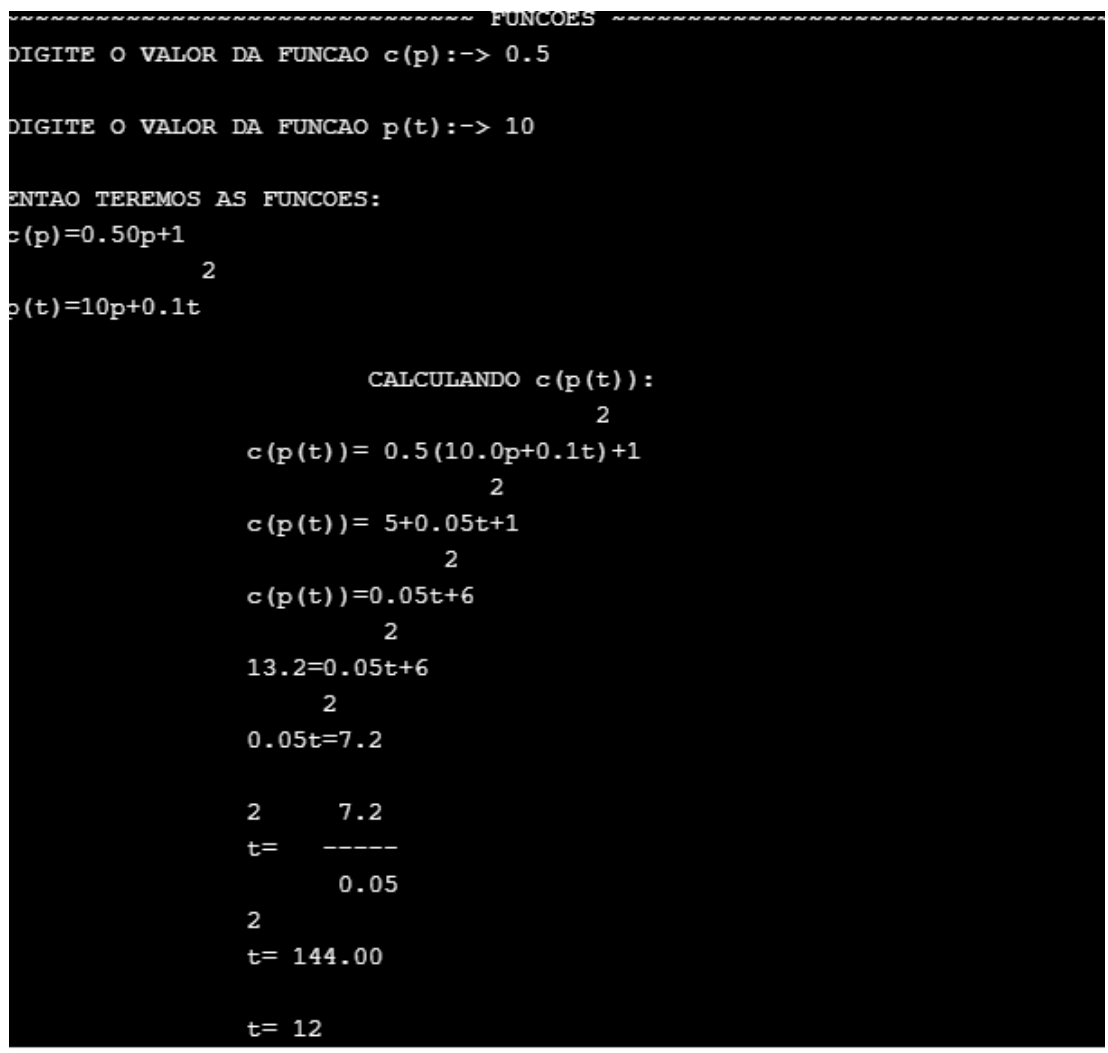

Figura 4.8: Resultado da execução do Exemplo 4 em C 


\subsection{Exemplo 5}

Resolução em C do exemplo 5 deste livro não é aplicado em um algoritmo.

\subsection{Exemplo 6}

Resolução em C e sua execução em duas partes:

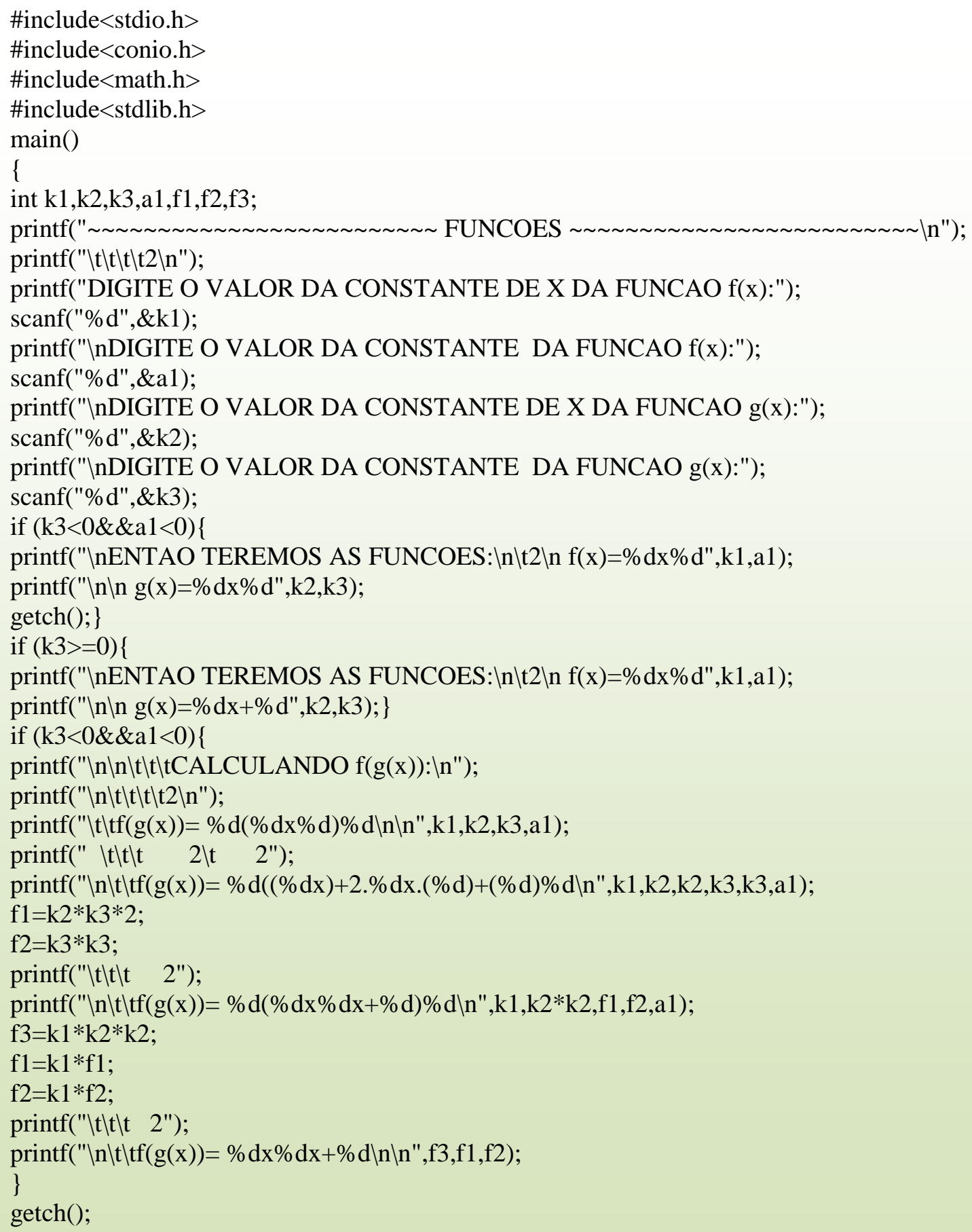

Figura 4.9: Exemplo 6 em C - Parte 1 


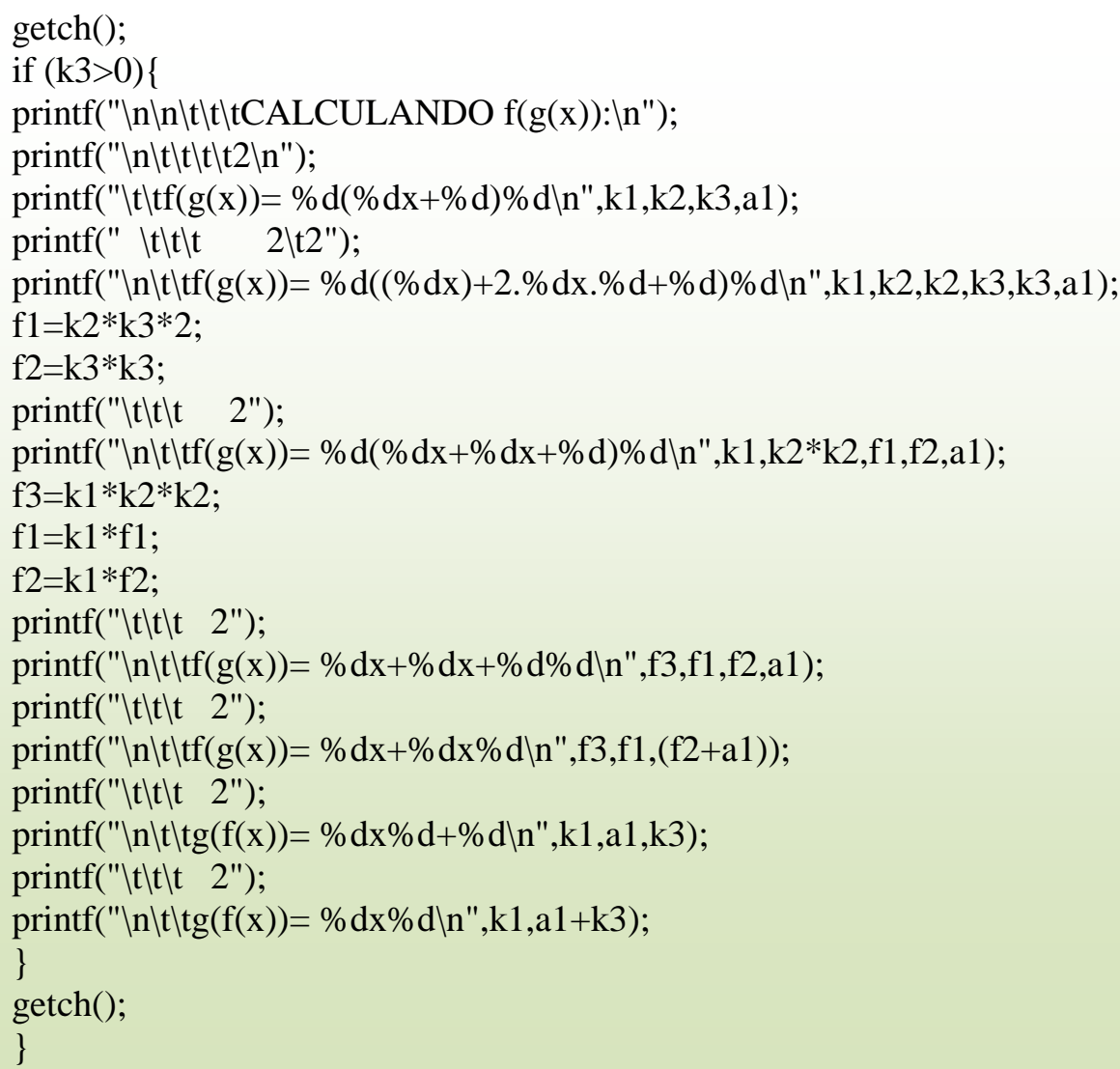

Figura 4.10: Exemplo 6 em C - Parte 2

Resultado da execução do programa do Exemplo 6

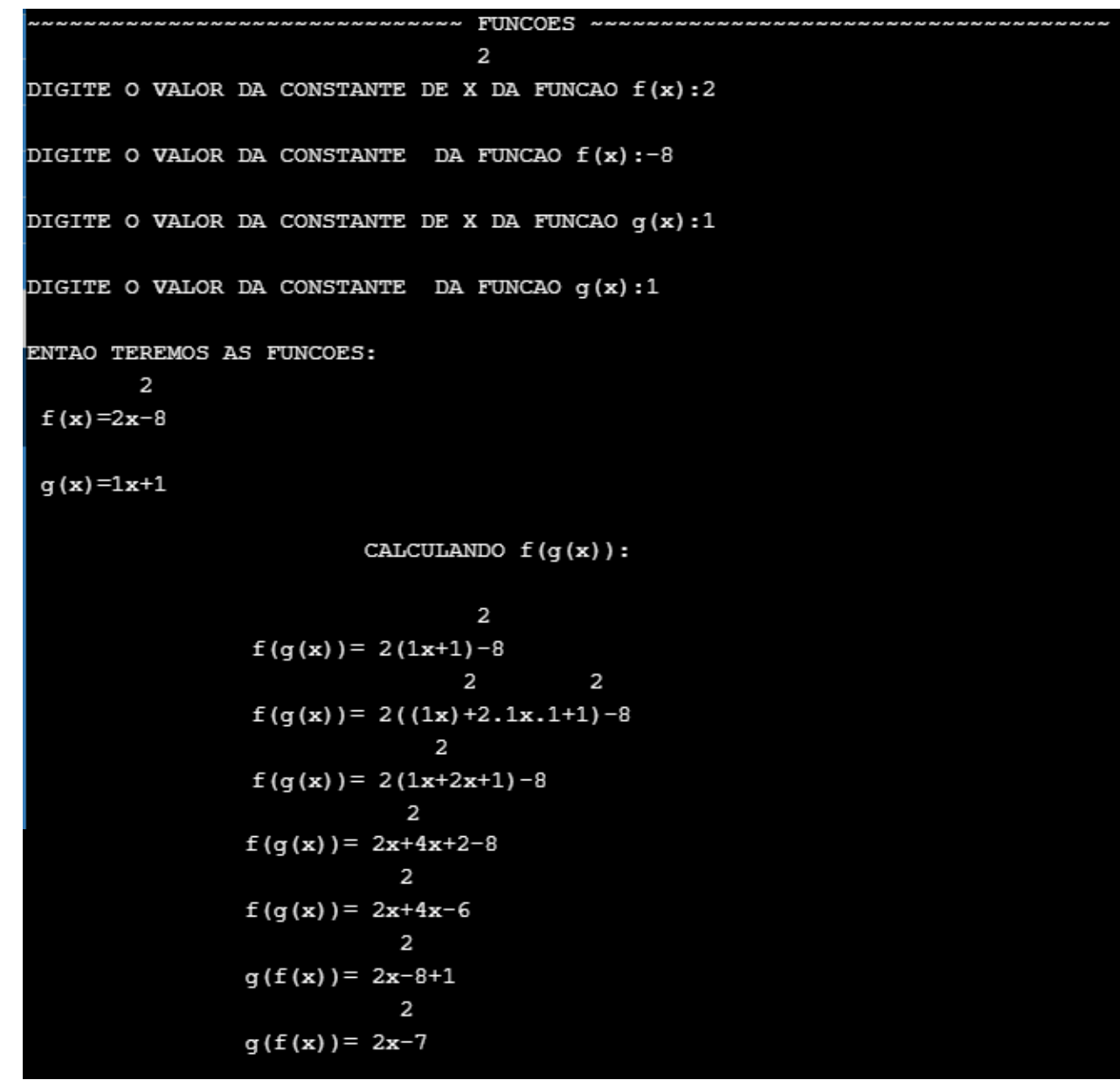

Figura 4.11: Resultado da execução do Exemplo 6 em C 


\subsection{Exemplo 7}

Resolução em C e sua execução:

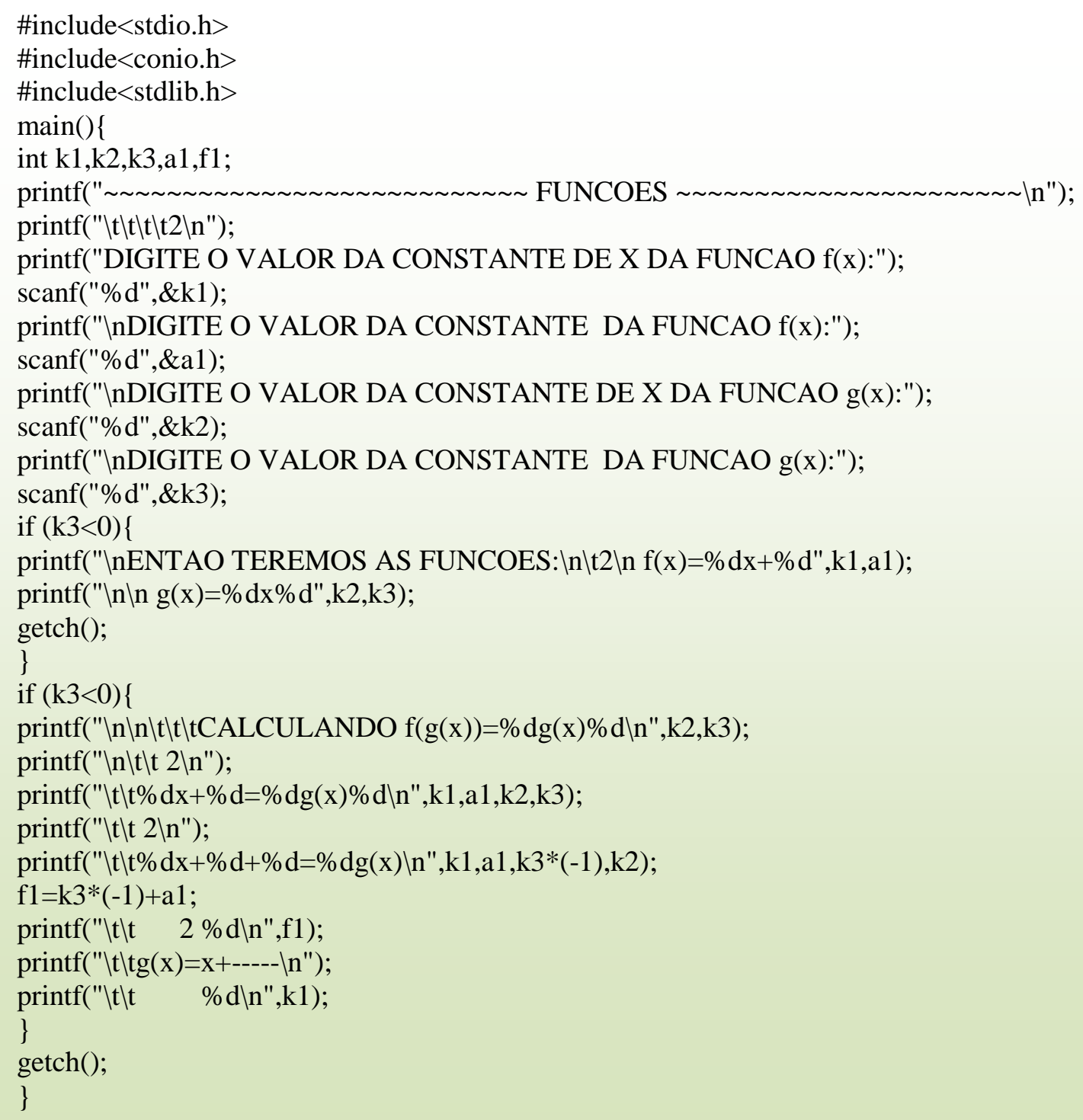

Figura 4.12: Exemplo 7 em C 
Resultado da execução do programa do Exemplo 7

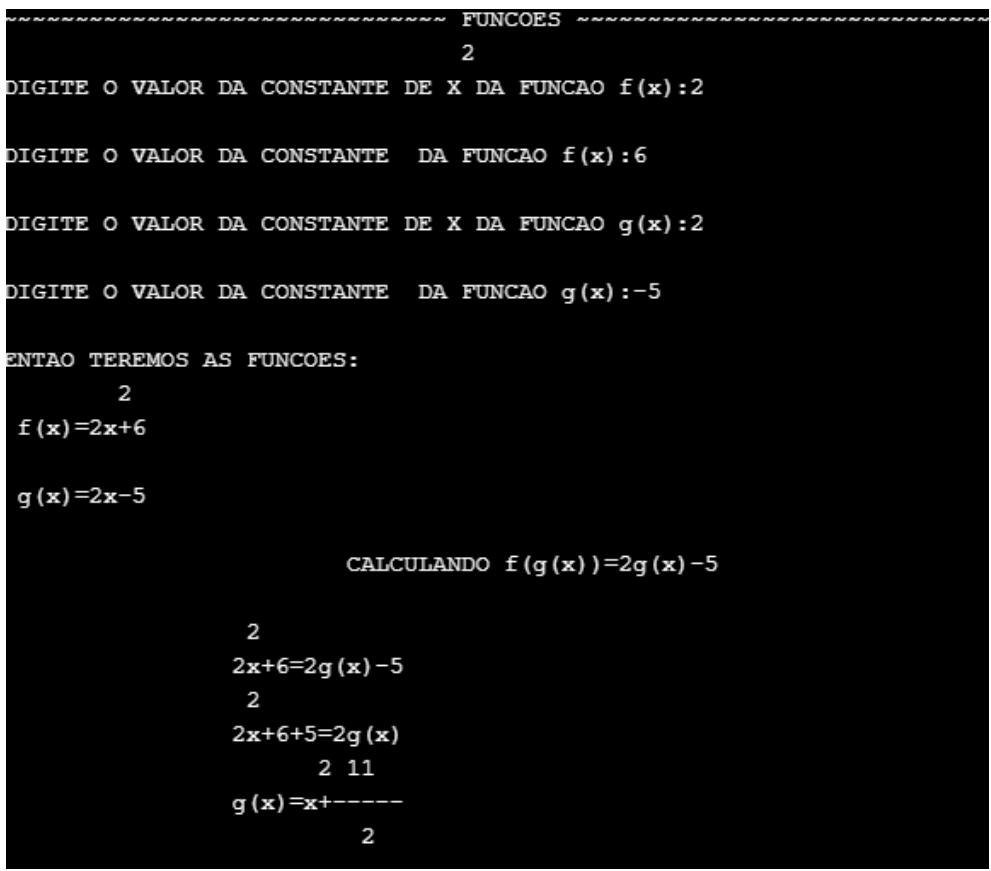

Figura 4.13: Resultado da execução do Exemplo 7 em C

\subsection{Exemplo 8}

Resolução em C e sua execução:

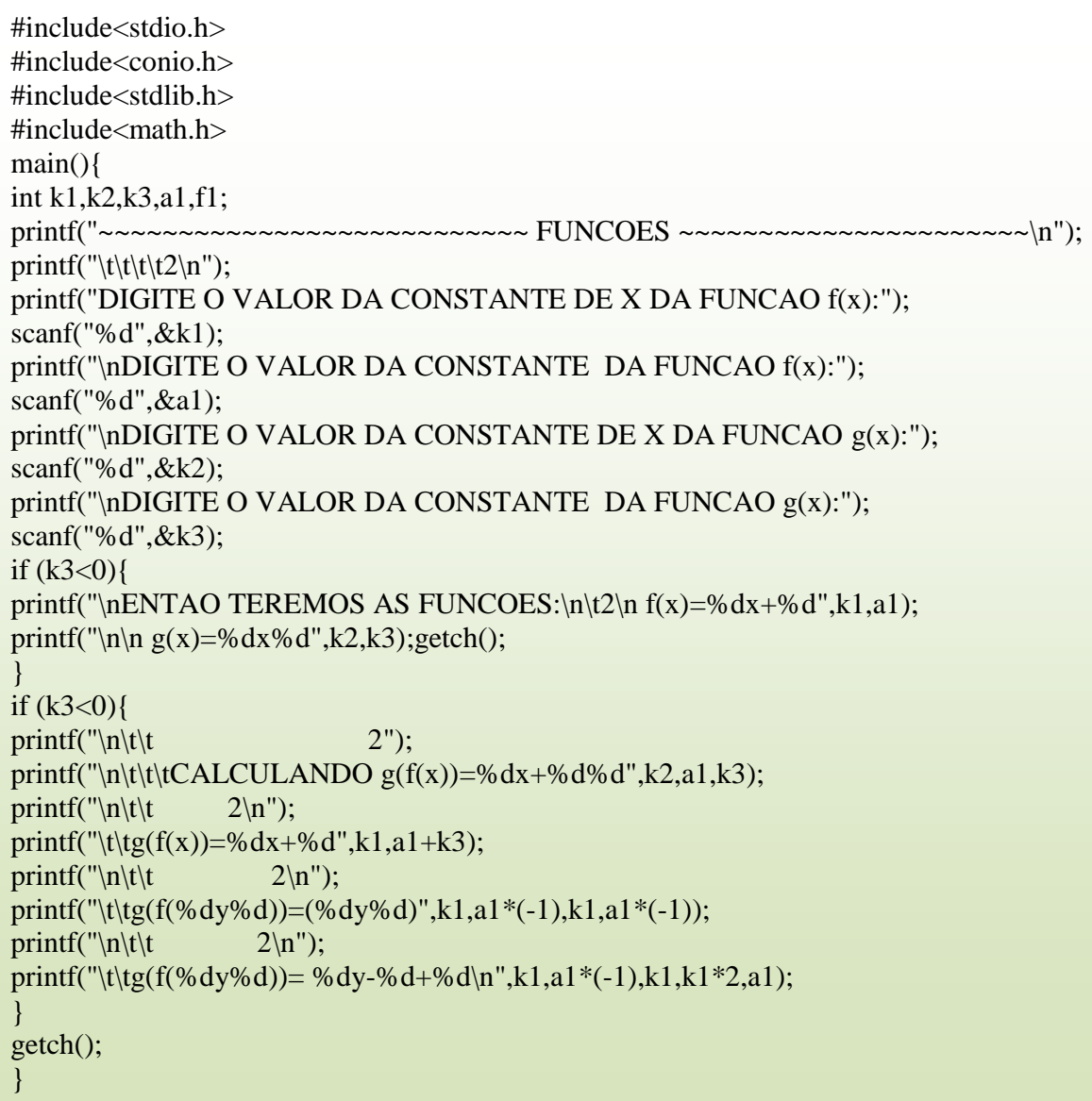

Figura 4.14: Exemplo 8 em C 
Resultado da execução do programa do Exemplo 7

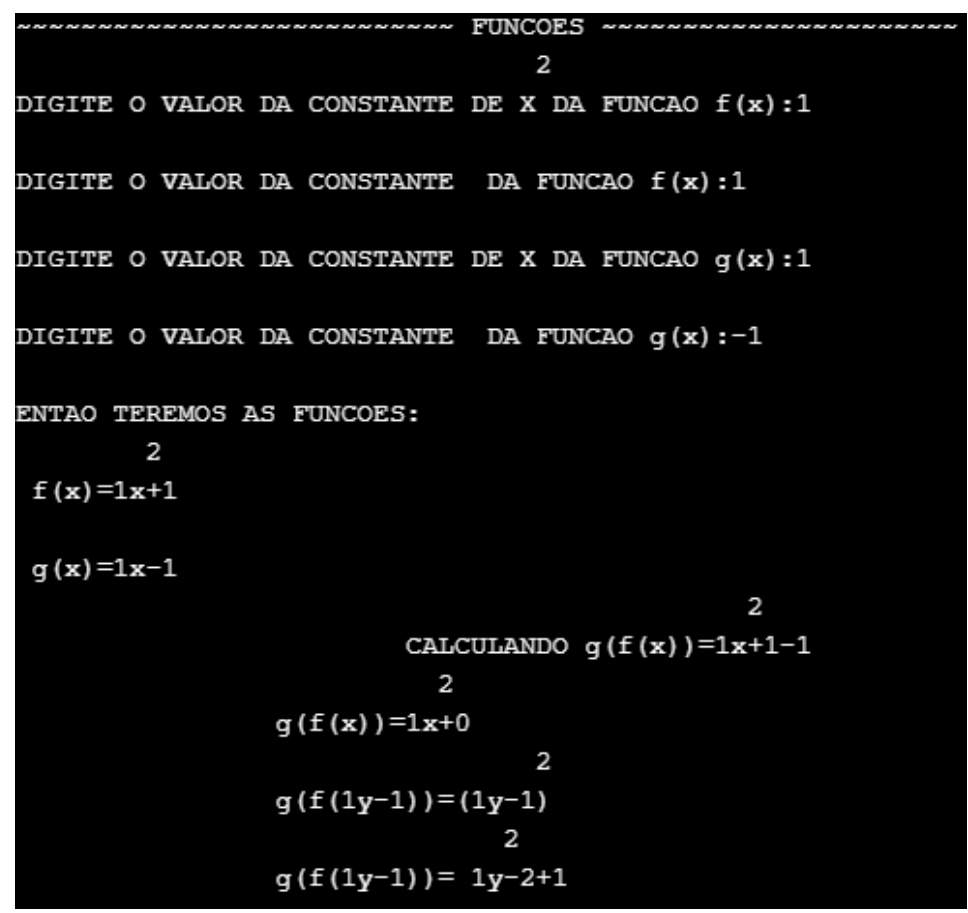

\subsection{Exemplo 9}

Resolução em C e sua execução em duas partes:

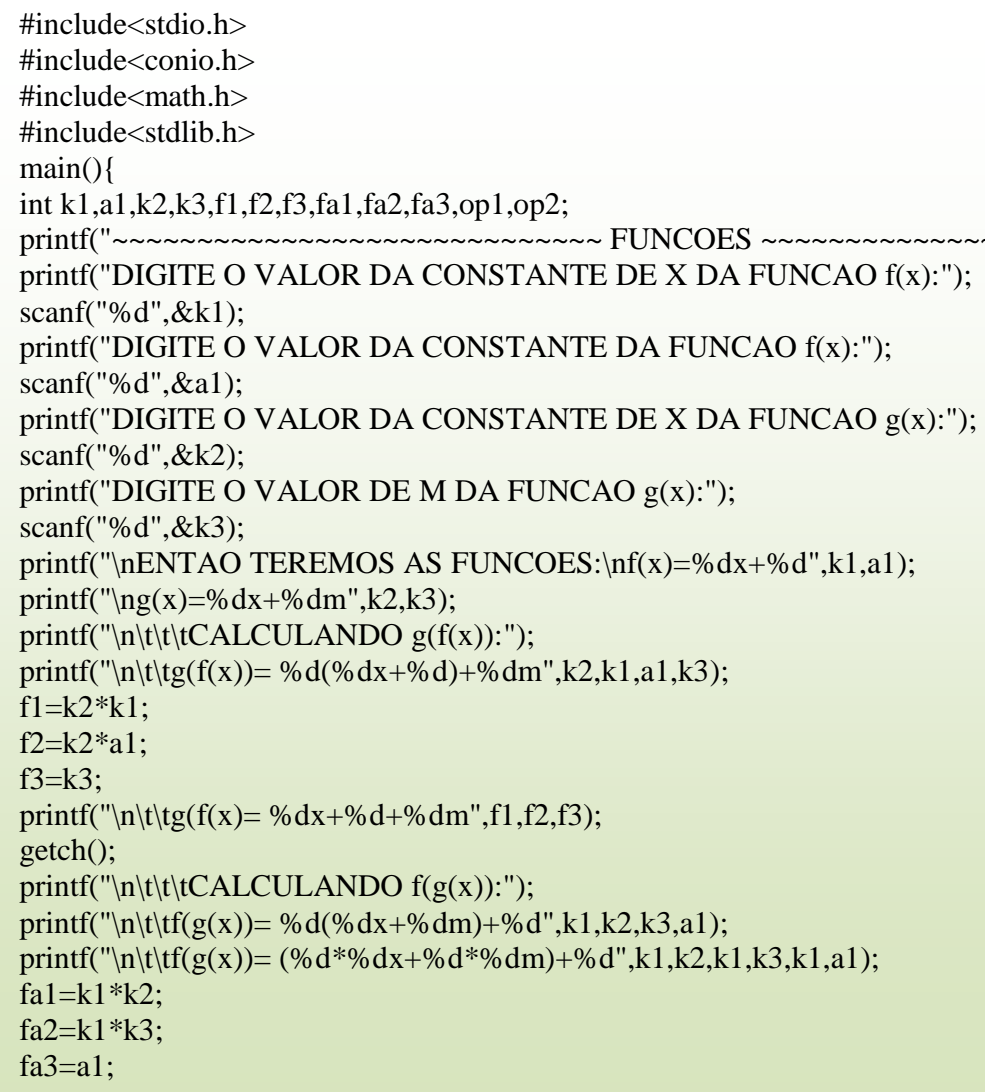

Figura 4.16: Exemplo 9 em C - Parte 1 
printf("Inltttf(g(x)=\%dx+\%dm+\%d",fa1,fa2,fa3);

printf("|n|t|t|tPARA QUE $\mathrm{f}(\mathrm{g}(\mathrm{x}))=\mathrm{g}(\mathrm{f}(\mathrm{x}))$ TEREMOS:");

printf("Inlttt\%d+\%dm=\%dm+\%d",f2,f3,fa2,fa3);

printf("|nlt|t\%d-\%d=\%dm-\%dm",f2,fa3,fa2,f3);

op1=f2-fa3;

op2=fa2-f3;

printf("Inlt|t \%d=\%dm",op1,op2);

printf("In|t|tf(6)=\%d*\%d+\%d",k1,op1,a1);

printf("Inltttf(6)=\%d+\%d",k1*op1,a1);

printf("Inlt ttf(6)=\%d",(k1*op1)+a1);

getch();

\}

\subsection{Exemplo 10}

Figura 4.17: Exemplo 9 em C - Parte 2

Resolução em C e sua execução:

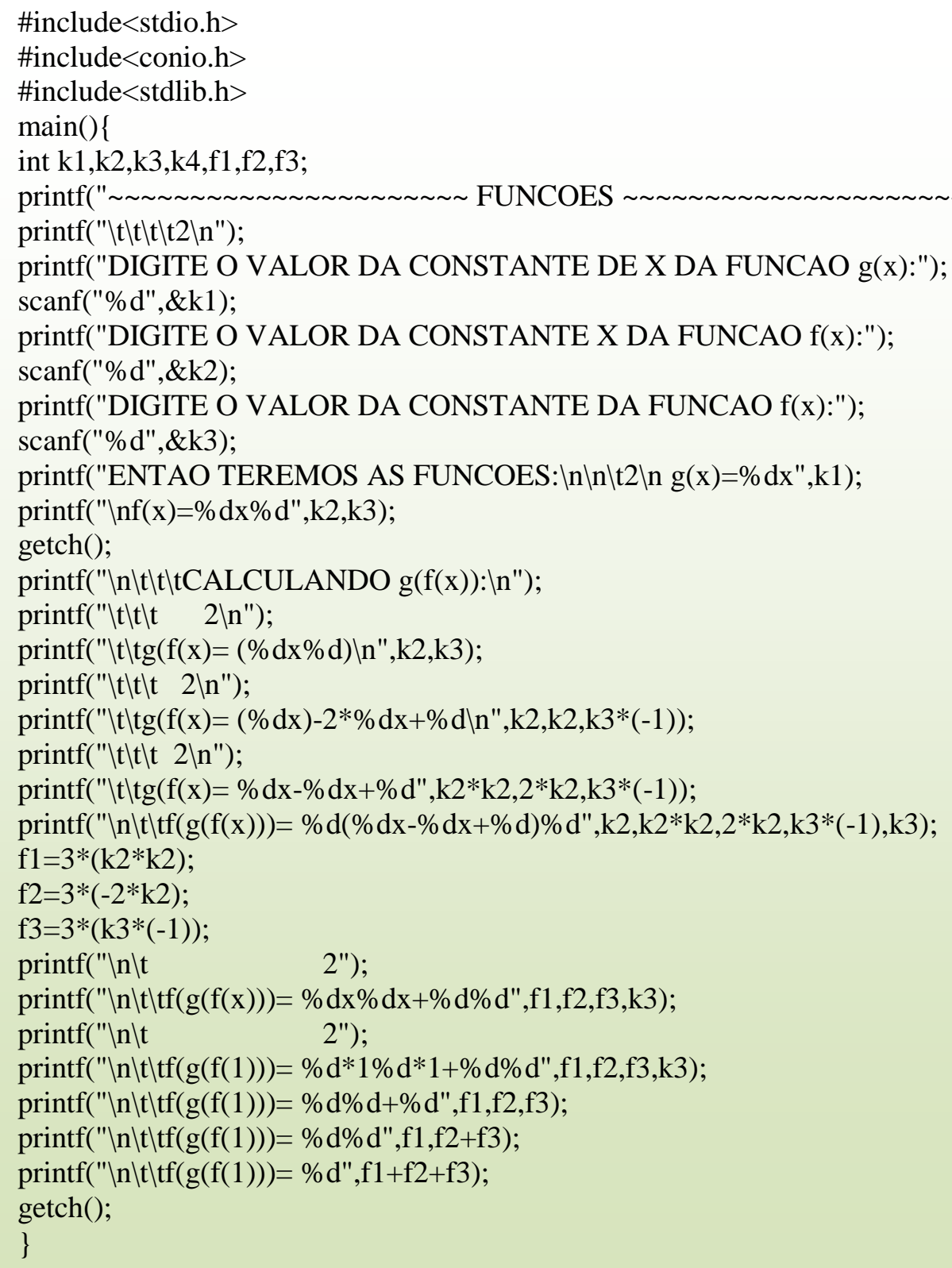

Figura 4.18: Exemplo 10 em C 


\subsection{Exemplo 11}

Resolução em C e sua execução:

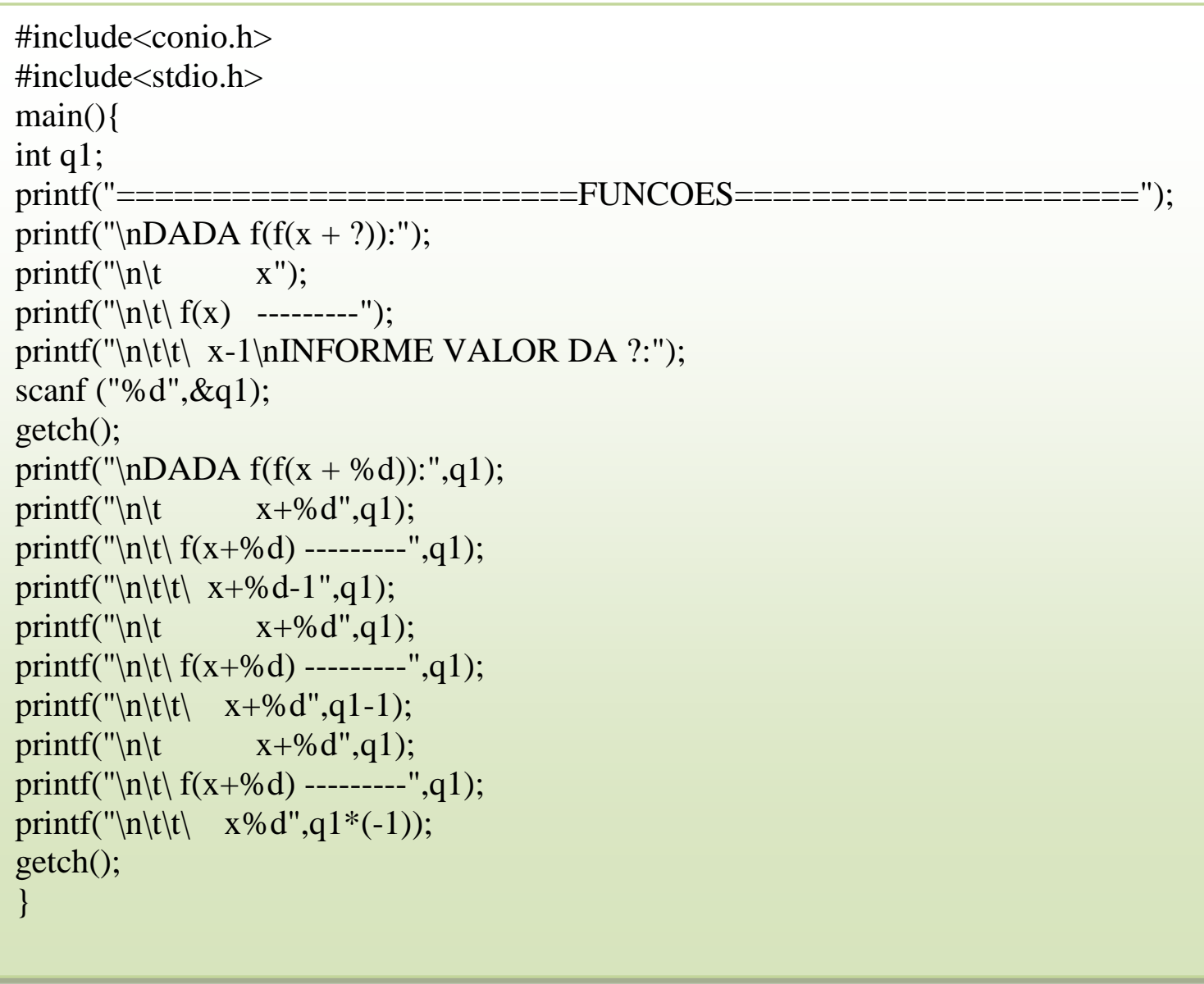

Figura 4.19: Exemplo 11 em C

Resolução em C e sua execução:

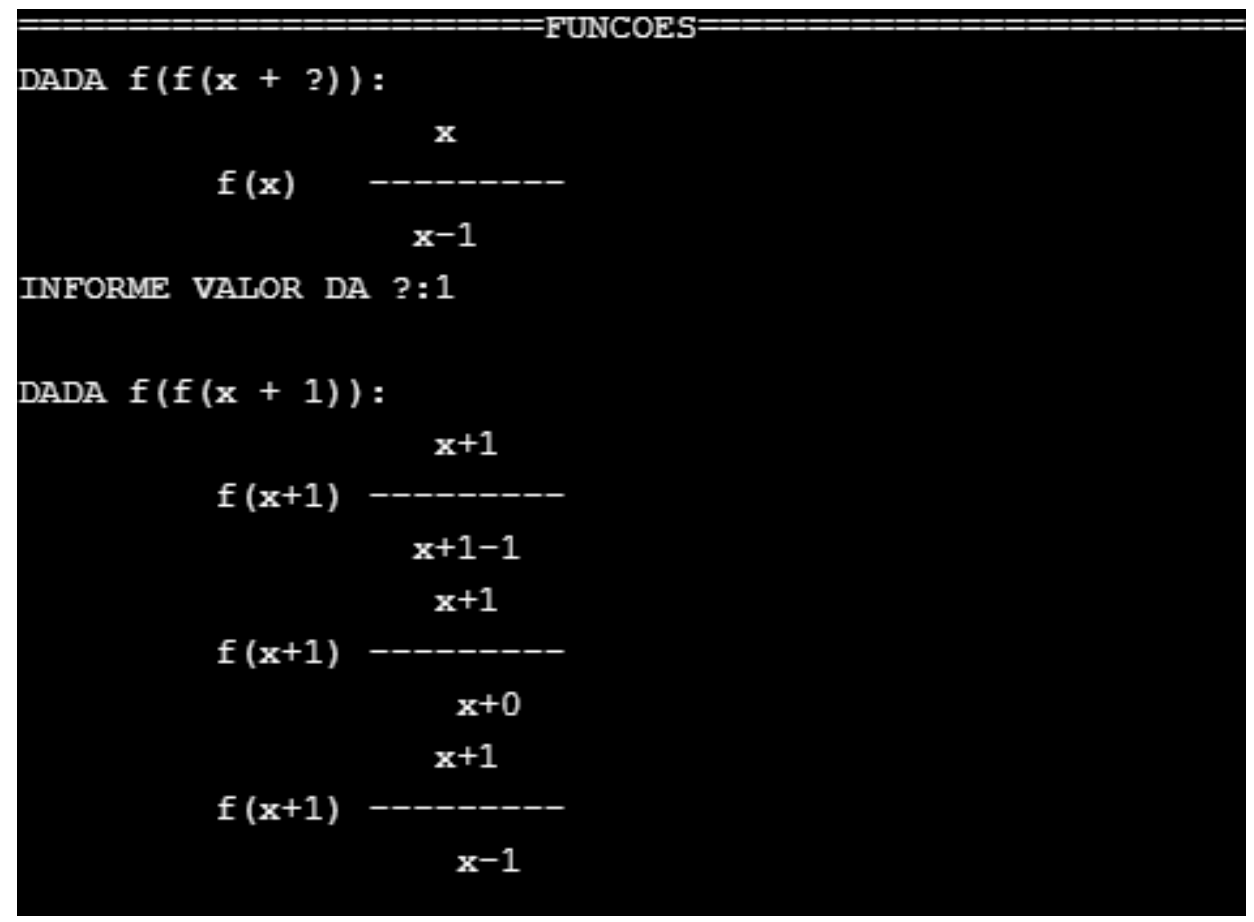

Figura 4.20: Resultado da execução do Exemplo 11em C 


\subsection{Exemplo 12}

Resolução em C e sua execução:

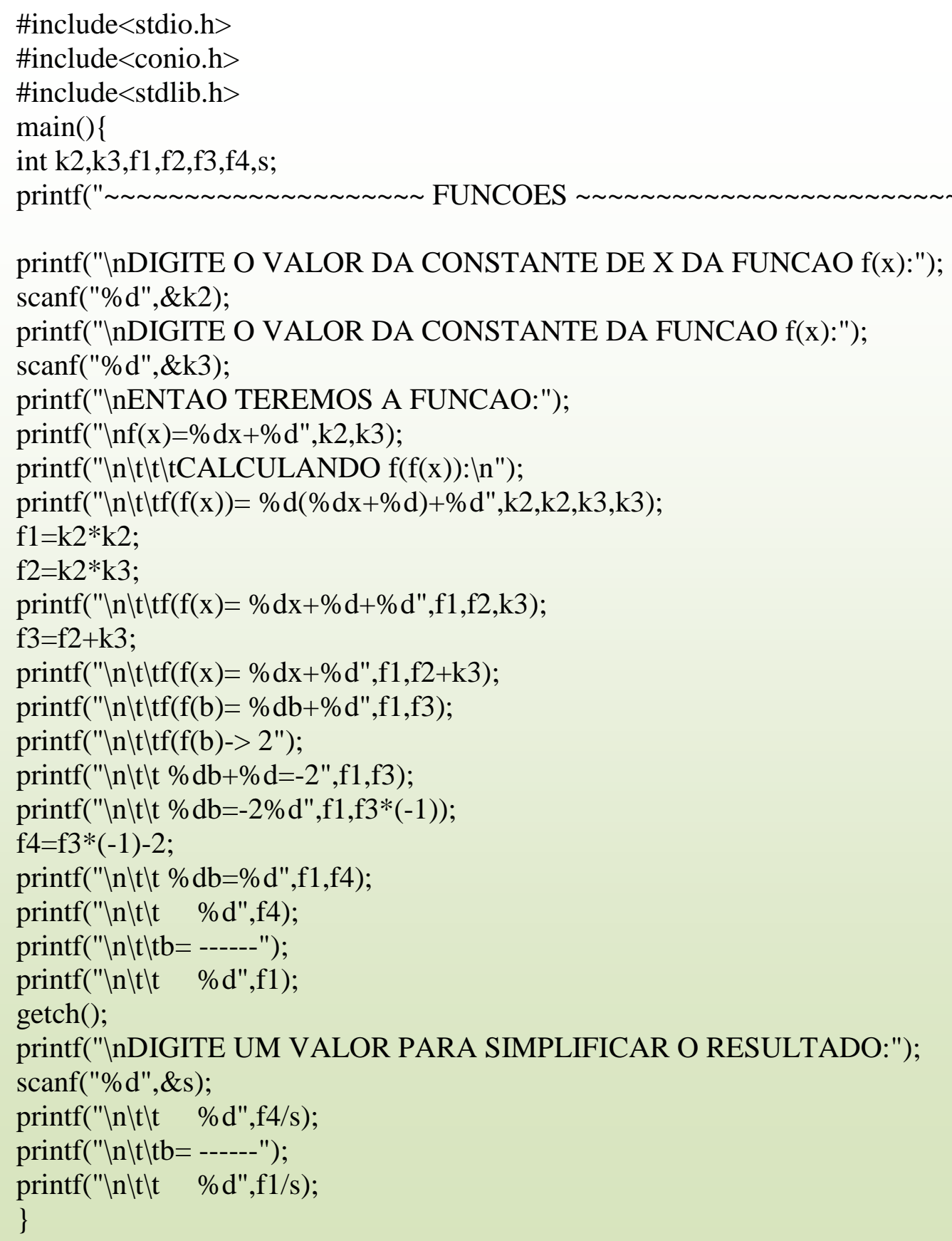

Figura 4.21: Exemplo 12 em C 
Resolução em C e sua execução:

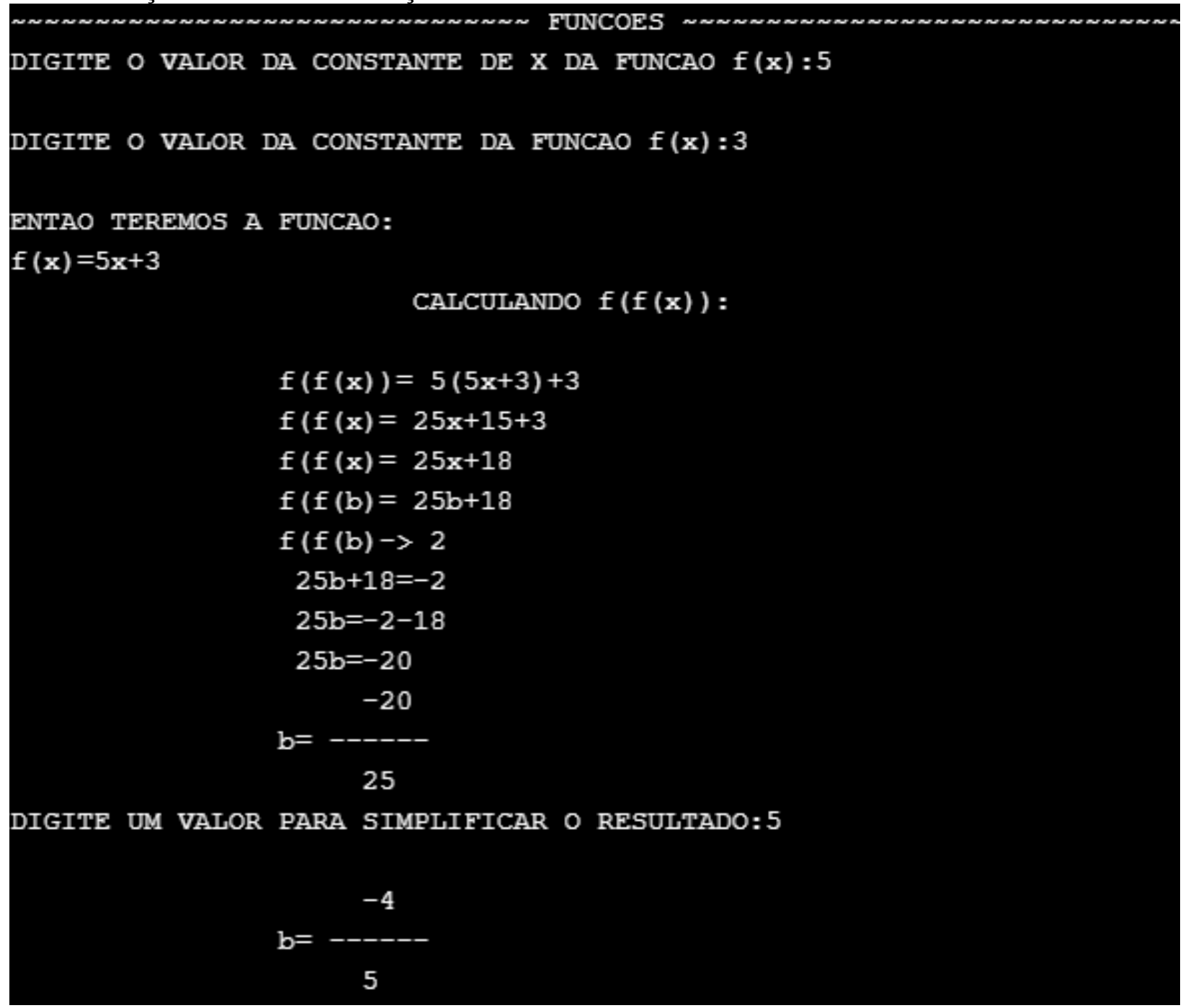

Figura 4.22: Resultado da execução do Exemplo 12 em C

\subsection{Exemplo 13}

Resolução em C e sua execução:

\#include<conio.h>

\#include<stdlib.h>

main ()\{

int $\mathrm{k} 2, \mathrm{k} 3$;

printf("

FUNCOES ");

printf("InDIGITE O VALOR DE ax DA FUNCAO f(x):");

scanf("\%d",\&k2);

printf("InDIGITE O VALOR DA CONSTANTE DA FUNCAO f(x):");

scanf("\%d",\&k3);

Figura 4.23: Exemplo 13 em C - Parte 1 


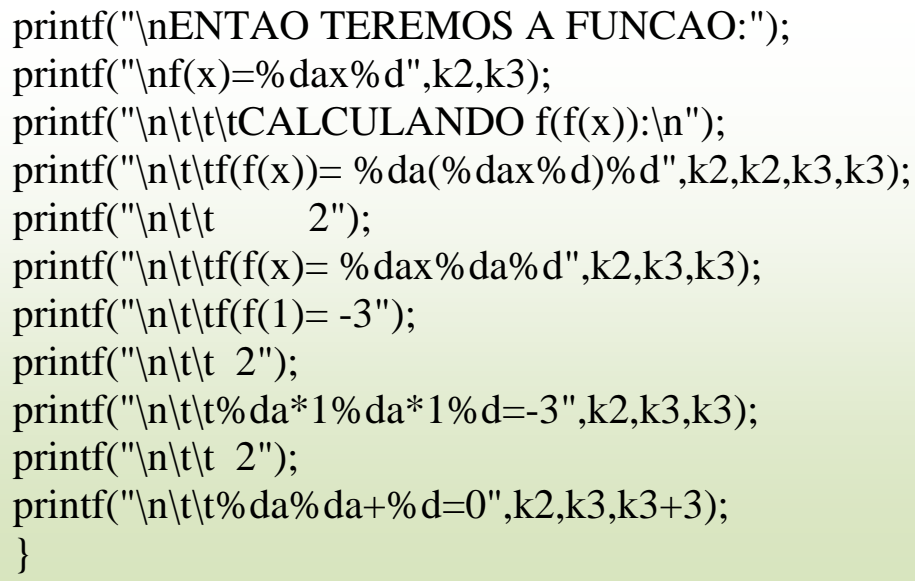

Figura 4.24: Exemplo 13 em C - Parte 2

Resolução em C e sua execução:

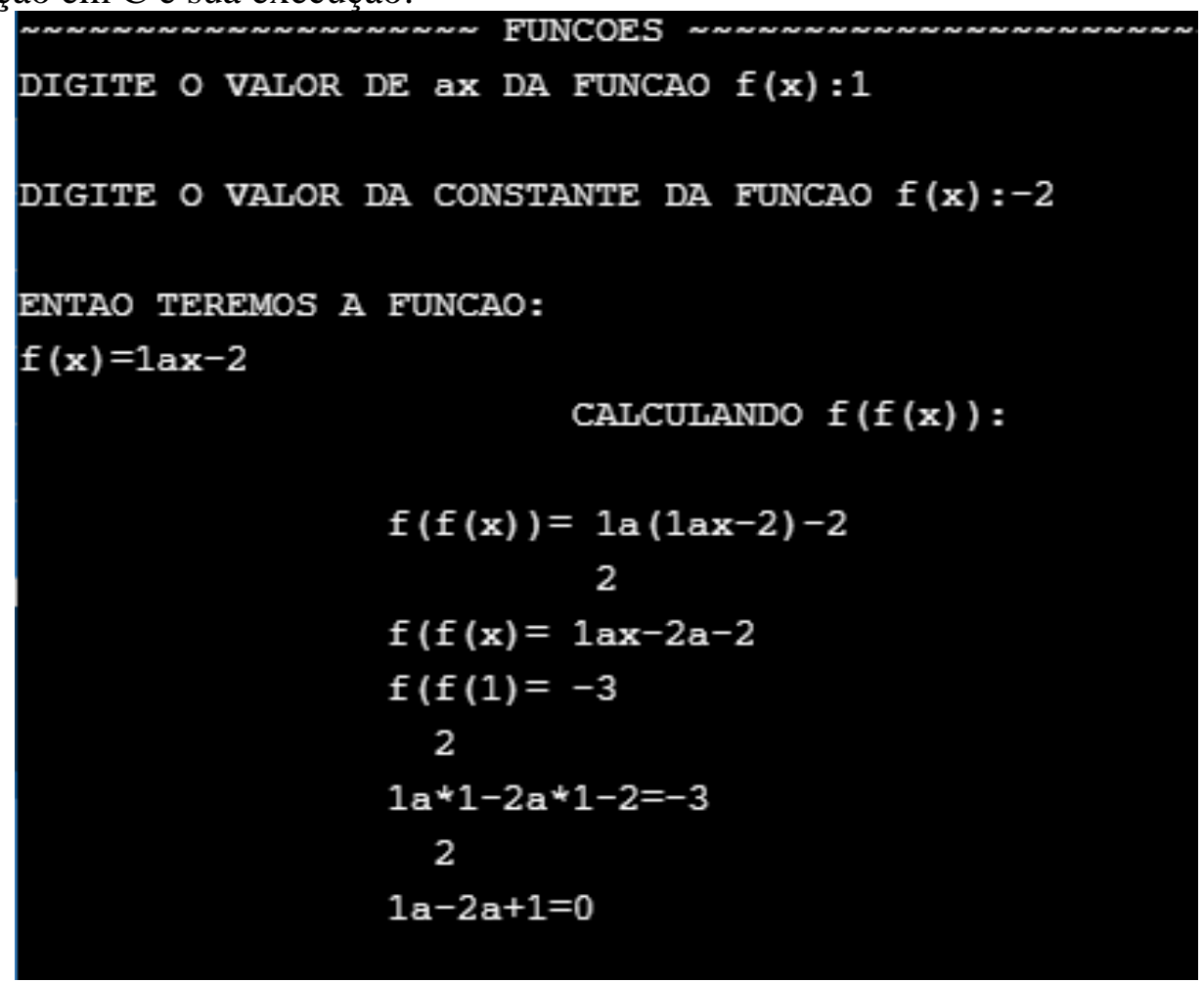

Figura 4.25: Resultado da execução do Exemplo 13 em C 


\section{Desafios para o leitor!}

1. Transforma os códigos em C para C++

2. Obter exemplos e exercícios de funções e portar para uma linguagem de programação

3. Pensar em soluções mais dinâmicas para atender diversos cenários através da programação 


\section{Anotações Matemáticas}




\section{Anotações de Programação em C}




\section{Referências Bibliográficas}

BURAK, D., Modelagem Matemática e a Sala de Aula In: I EPMEM -Encontro Paranaense da Modelagem Na Educação Matemática., 2004.Londrina. Anais do I EP- MEM, 2004.

DEITEL, Paul. DEITEL, Harvey. C: Como Programar. Editora Makron Books, $6^{\text {a }}$ edição, 2011.

DUVAL, $\mathrm{R}$ Ver e ensinar a matemática de outra forma: entrar no modo matemá- tico de pensar: os registros de representação semiótica São Paulo: PROEM, 2011.

IEZZI, G. [et al] Matemática ciências e aplicações, Vol. 1. São Paulo, Saraiva, 2013.

IEZZI, MOREIRA, M. A., MASINI, E. A. F. S Aprendizagem significativa: a teoria e textos complementares. São Paulo, Livraria da Física, 2011.

LIMA, E. L., Números e Funções Reais. Rio de Janeiro:SBM, 2013

SOUZA, J. R., GARCIA, J. S. R Contato Matemática Vol.1 São Paulo, FTD, 2016. 